\title{
SERIE LÍTICA DEL PERIODO PALEOINDIO DE TIPOLOGÍA JOBOIDE, ORIGINARIA DE LA PENÍNSULA DE PARAGUANÁ AL NOR-OCCIDENTE DE VENEZUELA, EN LA COLECCIÓN DEL MUSEO DE ARQUEOLOGÍAY ANTROPOLOGÍA DE LA UNIVERSIDAD NACIONAL MAYOR DE SAN MARCOS
}

\author{
JUANYATACO' \\ Museo de ARQueología y ANTROPOlogía - UNMSM \\ capchajuan@gmail.com \\ CAMILO MORÓN \\ UnIVERsidAd NaCIONAL EXPERIMENTAL FRANCISCO DE MIRANDA \\ camilomoron@gmail.com
}

\section{RESUMEN}

El análisis lítico de una colección integrada por 27 piezas provenientes de la República Bolivariana de Venezuela, conservada en el Museo de Arqueología y Antropología de la UNMSM, ha puesto al descubierto la presencia de preformas bifaciales, desechos de talla, útiles y puntas sobre cuarcita. Estas han sido determinadas del tipo Joboide (aprox. 13.664 calBC-14.850 calBC) proveniente del cerro Santa Ana, península de Paraguaná. Debido a que estamos frente a una colección única en el Perú y su asociación Joboide, hemos procedido a relacionar su asociación temporal con los fechados obtenidos del sitio Taima-Taima empleando para ello la calibración radiocarbónica.

Palabras Clave: Paleoindio, Venezuela, Cruxent, Paraguaná, Taima-Taima.

\begin{abstract}
The research of twenty seven archaeological pieces from collection of Venezuela Republic conserved in San Marcos University Museum in the Archaeological and Anthropological San Marcos University Museum, put in evidence the presence of bifacial performs, debris, stone tools and points of quarzites type. These have been determined the type Joboide (13.664 calBC-14.850 calBC) coming from cerro Santa Ana, Peninsula de Paraguaná. Due to be the only unique collection in Peru and their Joboide association, we have proceeded to relate their temporal association with the radiocarbon dates obtained from Taima-Taima site using the radiocarbon calibration.
\end{abstract}

KEYwords: Paleoindian, Venezuela, Cruxent, Paraguaná, Taima-Taima.

i Curador Lítico del Museo de Arqueología y Antropología de la Universidad Nacional Mayor de San Marcos (UNMSM).

ii Historiador y Etnólogo de la Universidad Nacional Experimental Francisco de Miranda (UNEFM). Doctorando en Antropología en la Universidad de Los Andes (ULA). 


\section{INTRODUCCIÓN}

Los restos óseos de animales pleistocénicos en asociación con puntas de proyectil de tipología joboide forman parte de las evidencias encontradas en distintos yacimientos arqueológicos asociados al Pleistoceno Terminal en el occidente de Venezuela, José María Cruxent, ha sido uno de los principales investigadores que ha dejado una serie de propuestas y definiciones bases en la arqueología venezolana. Sus ideas hoy en día urgen ser reevaluadas, comprobadas y ampliadas.

Investigaciones efectuadas desde el 2010 en el Museo de Arqueología y Antropología de la Universidad Nacional Mayor de San Marcos de Lima (MAA-UNMSM), han revelado la presencia de 27 piezas arqueológicas catalogadas como de tipología joboide (Cruxent 1956, 1962; Cruxent \& Ruose 1956, 1958; Morón 2011), de seis yacimientos arqueológicos procedentes del cerro Santa Ana, en la península de Paraguaná, al Nor-Occidente de Venezuela. Estas piezas fueron donadas por Cruxent al Museo De Arqueología Antropología De La Universidad Nacional Mayor De San Marcos hacia 1980. Somos conscientes que el tamaño de la muestra no puede ser el adecuado para efectuar análisis detallados y llegar a conclusiones rigurosas; sin embargo, la colección es inédita y conociendo los contados análisis líticos (Cruxent 1967, 1979; Ochsenius 1979; Szabadics y Torrealba 2000; Oliver \& Alexander 2003) de otros materiales que provengan de la península de Paraguaná, esta se torna de gran importancia y la información que brindamos en el presente artículo puede ser una referencia útil para futuras investigaciones. Recalcamos que viendo que en la península de Paraguaná aún no se han realizado trabajos detallados sobre el instrumental de tipología paleoindia procedente de la península de Paraguaná, y menos se han publicitado ampliamente estos hallazgos, hemos procedido a realizar el análisis de esta colección aplicando la metodología de Cadena Operatoria logrando identificar al menos de manera preliminar segmentos de la secuencia de reducción de estos artefactos bifaciales. Todo trabajo arqueológico carece de valor sino se aborda, de manera conjunta, la temporalidad de los artefactos. Por tal razón realizamos una calibración de los fechados radiocarbónicos del sitio más representativo de Venezuela, Taima-Taima. Sabemos que materiales líticos desde el punto de vista morfotecnológico son del tipo El Jobo los cuales guardan estrecha relación temporal con Taima-Taima y hemos creído conveniente abordar sus fechados y calibrados a años calendáricos nuestros empleando el programa Oxcal 4.1 y la curva de calibración InCal09. Los resultados de la temporalidad obtenida son asociados a esta colección arqueológica.

\section{UBICACIÓN GEOGRÁFICA Y GEOLOGÍA HISTÓRICA Del estado Falcón y la península de Paraguaná}

Los materiales arqueológicos de tipología joboide en la colección del MAA-UNMSM fueron colectados en la superficie de las laderas del cerro Santa Ana por J. M. Cruxent y Patrick Gallagher entre 1979 y 1980. El cerro Santa Ana es un promontorio localizado a $11^{\circ} 49^{\prime} 24,83^{\prime \prime} \mathrm{N}$ y $69^{\circ} 57^{\prime} 00,56^{\prime \prime} \mathrm{O}$ (vide, plano ubicación, Mapa).

El territorio geopolítico que del estado Falcón corresponde con una de las ocho provincias fisiográficas, descritas por Liddle (1928) para Venezuela y que aún hoy en día son consideradas válidas (Schwarck 1956). La región de Falcón está comprendida entre el lago de Maracaibo al Oeste, la cordillera de los Andes al Sureste y el mar Caribe al Norte. Está integrada por el territorio del estado Falcón y parte de los estados Lara y Yaracuy. En ella aflora una amplia franja de sedimentos terciarios que han sido plegados a lo largo de rumbos uniformes en sentido Este-Oeste. Estas estructuras tienen expresión topográfica en una serie de sierras alargadas aproximadamente paralelas entre sí. Hacia el Sureste, se convierten gradualmente en los contrafuertes andinos y en los terrenos de la depresión del estado Lara; al Noroeste están bordeadas por una estrecha franja de planicies costeras áridas que incluyen la península de Paraguaná y el istmo de los Médanos de Coro. 


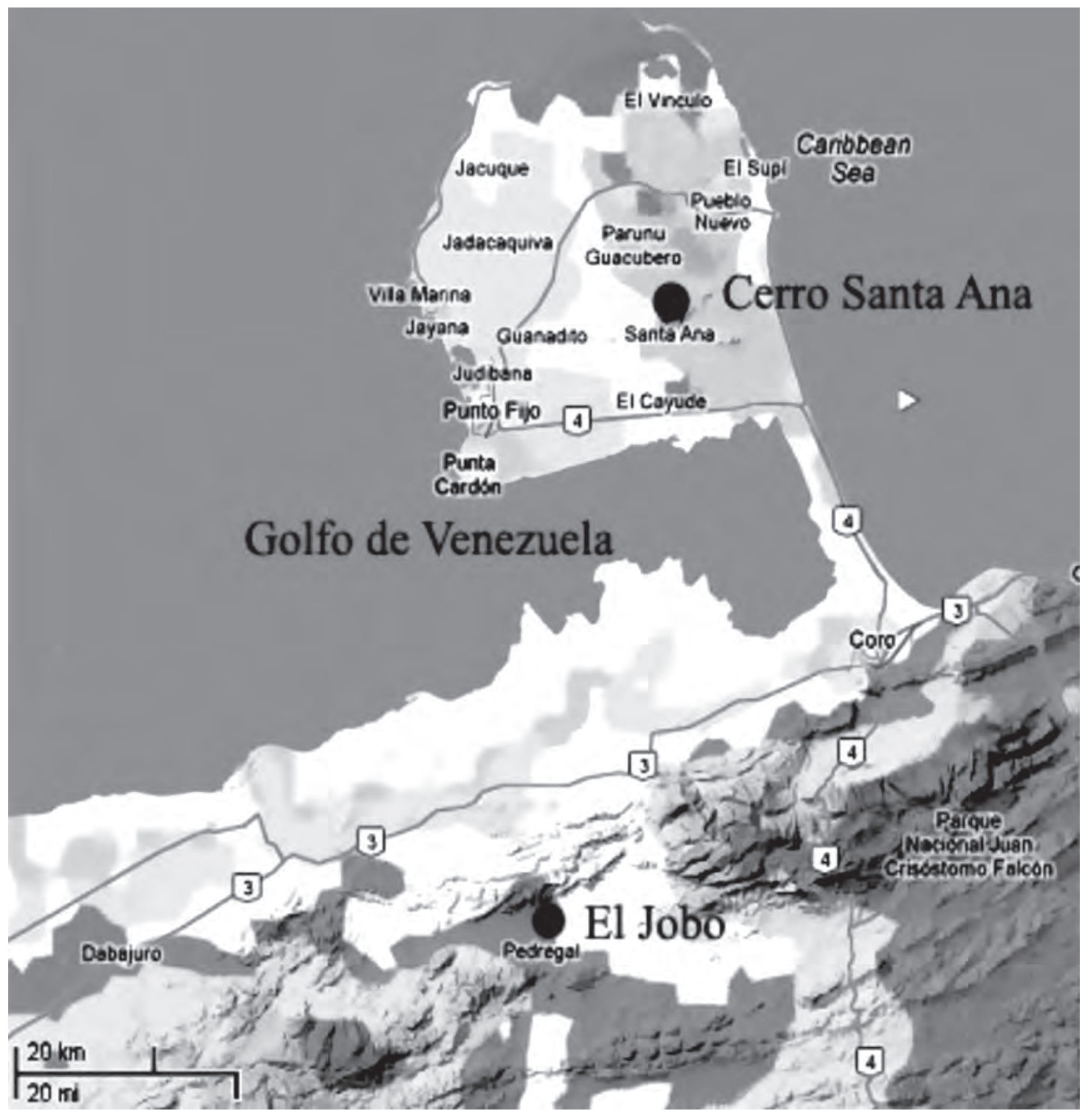

\section{Mapa de ubicación del cerro Santa Ana y El Jobo.}

En la parte central de Falcón afloran sedimentos del Oligoceno, bordeados hacia el Norte y el Sur por franjas de sedimentos del Mioceno. En la parte meridional se observan afloramientos importantes del Eoceno, marino o continental, en contacto con extensos afloramientos de rocas cretácicas que se extienden más al Sur. Algunas masas de rocas ígneas intrusivas afloran en la región; la mayor está constituida por rocas básicas en contacto con metasedimentos hacia la parte centro-occidental de la península de Paraguaná. Constituyen allí una unidad topográfica característica: el cerro Santa Ana o Chamuriana, según el toponímico indígena conservado en la tradición oral de la península (Hernández 1984, 1988 y 2000). Las rocas ígneas metamórficas son probablemente de edad cretácica (Schwarck 1956). Se ha propuesto la hipótesis que el cerro Santa Ana sea un volcán alóctono (Villavicencio 1985; Bessada 2011: Com. Pers.). Esta diversidad petrológica puede explicar, en parte, las diversas industrias líticas que han sido encontradas y descritas en la región coriana (Cruxent y Rouse 1956, 1958; Rouse y Cruxent 1963c; 
Cruxent y Ochsenius 1979, Cruxent y Gallagher 1979; Szabadics 1997; Oliver 1999 y 2010; Szabadics y Torrealba 2000; Morón 2007, 2010 y 2011). Decimos que puede adelantar o ser una explicación parcial, en la medida que aún quedan por determinar las relaciones tipológicas y cronológicas entre las colecciones del material lítico provenientes de los diversos yacimientos, así como la elaboración de una cartografía georeferenciada precisa que comprenda tantos los yacimientos ampliamente estudiados, así como los recientemente registrados (Morón 2007, 2010 y 2011).

La columna estratigráfica de Falcón abarca sedimentos que van geocronológicamente desde el Cretácico hasta el Holoceno o Reciente, con espesores considerables de sedimentos terciarios, y facies diversas que van desde francamente marinas, hasta epicontinentales y continentales. A juicio de Schwarck (1956): "Tanto por las estructuras características, como por la abundancia de conjuntos faunísticos, esta región es, para los fines de estudio de paleontología y estratigrafía, una de las más interesantes del país." Las investigaciones de Cruxent y colaboradores, entre 1956 e inicios de la década de 1980, demostrarán in situ su importancia para el estudio del poblamiento temprano y el paleoindio en Sudamérica.

\section{Sobre el material lítico de la península de Paraguaná en custodia del Museo de Arqueología y Antropología de la Universidad Nacional MaYor de SAN Marcos (MAA-UNMSM)}

El material lítico en estudio ha sido ingresado y catalogado como de tipología joboide por Cruxent. Este dato se confirma mediante el inventario realizado en 1997 en el MAA-UNMSM. Asimismo, este documento solo presenta una somera lista de los materiales sin mayores detalles (Ugarte 1997: 124). Es a partir de las investigaciones realizadas desde el año 2010, donde se ha podido rastrear mayores datos de los materiales arqueológicos. Los rótulos de las piezas y una serie de visitas realizadas por el mismo Cruxent desde 1961 hasta de década de 1980 al MAA-UNMSM, pueden vincularse muy posible con la custodia de esta colección (Caycho 1957-1958: folios 1086, 1087).

Los materiales líticos arqueológicos fueron recuperados en Venezuela en abril de 1979, bajo la dirección de José María Cruxent y Patrick Gallagher (Centro de Investigaciones Antropológicas Arqueológicas y Paleontológicas, $\mathrm{CIAAP}^{1}$ ). Los rótulos de las piezas han permitido vincular a José María Cruxent como el director del trabajo de recolección. Además, nos ha brindado la localización geográfica de los artefactos líticos, los cuales provienen de seis yacimientos arqueológicos (Centro de Investigaciones Antropológicas Arqueológicas y Paleontológicas, CIAAP). Si bien han sido asociados a la tipología joboide, los artefactos no proceden de la región de Pedregal (Cruxent y Rouse 1956:172), sino de la península de Paraguaná. Por tal motivo creemos pertinente denominar a esta serie lítica como Joboide de la península de Paraguaná debido a que, presenta ciertas semejanzas con los materiales del tipo Jobo encontrados.

Sabiendo los datos, abordamos ut infra la morfotecnología del material lítico proveniente de El Jobo para establecer asociaciones certeras frente al material joboide procedente de la península de Paraguaná.

\subsection{SOBRE EL MATERIAL LÍTICO EL JOBO}

Las primeras exploraciones efectuadas por José María Cruxent e Irving Rouse en la región del Pedregal, estado de Falcón, localizado al noroeste de Venezuela, pusieron al descubierto un conjunto de sitios arqueológicos precerámicos que contienen una serie de puntas de proyectil y artefactos cuarcita y cuarzo

1 La documentación consultada ha sido realizada por el segundo autor. La fuente exacta sin referencia del año, es la siguiente: (s/f. sin fecha) Registro de Colecciones Líticas de Tipología Paleoindia en el estado de Falcón. Tomos I y II. Centro de Investigaciones Antropológicas Arqueológicas y Paleontológicas (CIAAP), Universidad Nacional Experimental Francisco de Miranda (UNEFM), Coro. Tomo I: Folios: 01-25. Tomo II: 19-72v. 
cristalino. La denominación joboide se debe a las semejanzas tipológicas y la coincidencia cronológica con el material de El Jobo, en el valle del río Pedregal (Cruxent \& Rouse 1958, 1961: 79; Cruxent 1956: 412-414). A partir de esta noticia una serie de comentarios generales fueron brindados a partir de la descripción morfológica de los artefactos generando controversias sobre el hallazgo (Cruxent \& Rouse 1956: 177-178). Debido a estos descubrimientos, Irving Rouse y José María Cruxent realizaron una serie de comparaciones morfológicas de las piezas de El Jobo con las puntas halladas en el sitio Ayampitin procedentes de Argentina; luego se las comparó con puntas de proyectil del tipo Proto-Tehuelchense procedentes del extremo norte de Patagonia y hasta con algunas puntas de proyectil descubiertas por Tschopick en Huancayo, Perú (Rouse \& Cruxent 1957: 412; Cruxent \& Rouse 1961: 81).

José María Cruxent e Irving Rouse (1961), caracterizan a El Jobo por: "sus puntas de proyectil, cuchillos y grandes raspadores o hachuelas, todos ellos de cuarcita"; además mencionan: "Designamos este material con el término "Paleo Indio", a causa de su extremo parecido con los complejos [...] del valle de México y de las llanuras de los Estados Unidos" (Cruxent \& Rouse 1961: 45). Durante estos primeros hallazgos los autores ponen de manifiesto que estos depósitos arqueológicos son superficiales y que no presentan prueba de antigüedad geológica ni radiocarbónica y tan solo exponen datos tipológicos generales de los artefactos (Cruxent \& Rouse 1961: 79). Tratando de solucionar el problema temporal de este complejo, los autores tomaron dos muestras de carbón, los cuales dieron como resultado fechas modernas (Cruxent \& Rouse 1961: 46; 81, 277). A pesar de ello, los hallazgos de El Jobo fueron determinados de manera preliminar al periodo temprano venezolano debido a su semejante asociación con contextos conformados por huesos de animales pleistocénicos procedentes de Santa Isabel de Iztapan del valle de México y a su semejanza de los artefactos liticos con el Ayampitín de Argentina (Cruxent \& Rouse 1961: 80-81; 277).

Más tarde, con el hallazgo de los materiales liticos arqueológicos del complejo Manzanillo, se realizan nuevamente similitudes tipológicas con los artefactos de tipología joboide y hasta con puntas del complejo pre-proyectil del extremo Oeste de los Estados Unidos. Empero, nuevamente una tipología general y fotografías sin mayores detalles son brindadas (Cruxent 1962: 577-578; cf. fig. 5, 6; Cruxent s/f: 3-4, figuras I-IX).

No es hasta 1963, cuando se publican los primeros fechados radiocarbónicos de los sitios Muaco y Rancho Peludo, los cuales dan credibilidad a los hallazgos de El Jobo (Rouse \& Cruxent 1963a: 537-539; 1963b: 3-10). Además, se determina de manera provisional la existencia de cuatro complejos sucesivos y se clasifica su ocupación por la presencia de una serie de artefactos, en donde los autores mencionan lo siguiente:

\footnotetext{
"Estudios geológicos posteriores han permitido clasificar provisionalmente los sitio en cuatro complejos sucesivos: Camare, Las Lagunas, El Jobo y Las Casitas, los cuales están correlacionados con las terrazas superior, superior media, inferior media e inferior del río Pedregal, respectivamente. Los sitios del complejo Camare carecen de puntas de proyectil, sólo tienen proto-hachas de manos burdas, raspadores pequeños y grandes lascas de cuarcita. Los artefactos del complejo Las Lagunas son más pequeños, la forma diagnóstica es una hoja bifacial que pudo haber sido usada como hacha de mano o como cuchillo, o tal vez fue enmangada a un lanzador. El complejo el Jobo tiene puntas de proyectil lanceoladas, a las cuales se añaden algunas puntas pedunculadas en el complejo Las Casitas" (Rouse \& Cruxent 1963b: 3).
}

Por otro lado, el sitio de Muaco localizado cerca de La Vela de Coro, en la costa noroccidental de Venezuela y a 80 kilómetros del sitio El Jobo, se excavó una trinchera de 20 x 12 m y se llegó a una profundidad de 2,5 m. Cruxent junto a José Arroyo y Gómez hallaron numerosos huesos de mastodonte, perezoso gigante y caballo sudamericano quemados y con huellas de corte antrópico. Al menos, un fragmento de punta lanceolada de tipología joboide, un raspador, un cuchillo y percutores fueron encontrados in situ, junto a los huesos de animales pleistocénicos. Es a partir de estas investigaciones que se toman dos muestras para fechados radiocarbónicos (0-999: 16,375₫400 B.P.) у (M-1068: 
$14,300 \pm 500$ B.P.), lo cual permite a Cruxent sugerir su ocupación durante el Pleistoceno Terminal. Sin embargo, efectos tafonómicos pueden haberse detectado debido a la presencia de esquirlas de botella de vidrio. Finalmente, los autores, con mucha cautela, ponen en discusión los datos obtenidos (Rouse \& Cruxent 1963a: 537; 1963b: 3-5; Cruxent s/f. 4, 5).

Seguidamente, las muestras de carbón y fechados obtenidos en 1961 del sitio Rancho Peludo localizado en la península de La Guajira son también controversiales y tomados con cautela por los autores (Rouse \& Cruxent 1963a: 538-539; 1963b: 5-7).

Una publicación medular de la arqueología venezolana fue realizada por Yale en 1963 "Venezuelan Archaeology" y posteriormente traducida el mismo año al español bajo el título "Arqueología Venezolana" (Rouse \& Cruxent 1963 c; d). Poniéndonos en el contexto de la época y sabiendo que la tecnología lítica estaba recién siendo estudiada, justipreciamos el valor que tienen estas publicaciones. Si bien es una publicación base de la arqueología venezolana no se publican datos detallados que aborden una definición clara de la morfotecnología y tipología lítica de la serie Joboide y estamos completamente seguros que José María Cruxent ha dejado una serie de propuestas preliminares con respecto a los artefactos del tipo El Jobo que tienen que ser desarrolladas, estudiadas a mayor detalle y puestas al día. Asimismo, se debe tener en cuenta al abordar este libro, que la versión inglesa (Rouse \& Cruxent 1963 c) y su traducción al español por Erika Wagner (Rouse \& Cruxent 1963d) han sufrido algunos cambios al momento de hacer la traducción de la terminología lítica y se ha detectado una serie de errores con respecto a la concordancia de las citas de algunas imágenes (cf. Rouse \& Cruxent 1963c: 29-32; 1963d: 36-38). Con respecto a la serie el Jobo al menos fotografías y figuras en diferentes publicaciones pueden ilustrar y dar idea de algunos detalles generales de los materiales y que a nuestro juicio pueden tratarse de preformas de piezas bifaciales, puntas bifaciales, puntas unifaciales de variadas morfologías y hasta una serie de artefactos como raspadores, lascas procedentes de reducción bifacial y unifaciales modificados (Vide, Cruxent \& Rouse 1961vol. 2: 39, 40; plancha 20; Rouse \& Cruxent 1963c: fig. 5, plate 2, plate 3; 1963d: lámina 2-3; Cruxent s/f: figuras I-IX).

Debemos aquí mencionar las excavaciones efectuadas en Taima-Taima y que se asocian, en primer lugar, al hallazgo de litos conformados por rodados que fueron clasificados como percutores, mortero y hachuela (Cruxent, 1967: 8-15). Más tarde, el trabajo efectuado en 1962 ha proporcionado datos muy tempranos de actividad humana en asociación con restos de fauna pleistocénica. Según los autores, junto a huesos de mastodontes (Stegomastodon waringi y Haplomastodon s.p.), que muy posible fueron fragmentados por el hombre, se encontraron también in situ tres fragmentos de puntas de tipología jodoide, un cuchillo unifacial o raspador y posibles hendidores (Bryan et al. 1978: 1275). En 1976, un equipo multidisciplinario trabaja en Taima-Taima y demuestra su prematura edad. Los datos más interesantes provienen de la unidad I, en donde se trata la evidencia de actividad humana (Bryan et al. 1978: 1275; 1979: 47-48; Rouse \& Cruxent 1963c: 36; 1963d: 44; Gruhn \& Bryan 1984: 128-137). Si bien Cruxent registra y describe cuatro puntas de proyectil solo una procede de la excavación la cual fue hallada en la cavidad pélvica de un mastodonte. Esta pieza es definida como una sección media de punta joboide sobre una arenisca cuarzosa, de forma rectangular, esta presenta una longitud de $40 \mathrm{~mm}$, ancho de 20 $\mathrm{mm}$ y espesor de $10 \mathrm{~mm}$. El soporte de la pieza al parecer es una lasca reducida bifacialmente y retocada muy probable, según Cruxent, por presión (Cruxent 1979: 77-78). Por otro lado, Cruxent arguye que la confección de las puntas de tipología joboide podían haber pasado por cuatro fases, primeramente la obtención de una lasca alargada, seguido de una puesta en forma por percusión, luego el empleo de percusión y empleo eventual de retoque y finalmente un delicado retoque en el borde la pieza por presión. La premisa de Cruxent puede ser cierta, pero creemos que esta aún es preliminar y carece de detalles que explique toda la secuencia de producción de las puntas de tipología joboide y ya el mismo investigador da cuenta de la diversidad de las puntas de proyectil con respecto a la categoría tipo (Cruxent 1979: 79). Cruxent describe al menos una lasca con presencia de córtex, se trata de la pieza ํㅡㄹ 211/2, encontrada in situ entre el cubito izquierdo y una costilla de mastodonte. En este caso llama la atención el tipo de la 
materia prima siendo un chert de grano fino traslucido que aflora en los alrededores. Si bien Cruxent no describe la pieza con mayores detalles y las asocia con otras piezas como la hallada en la excavación de 1968 (pieza no 3012), luego con otra procedente de superficie (pieza no 3008) él intuye que la posible función de ésta, pudo haber sido para modificar materiales blandos (e.g. madera y cortar tendones), pero esto lo realiza sin brindar detalles traceológicos de los mismos (Cruxent, 1979: 79-83). Otros artefactos de dificultosa determinación han sido clasificados como "tools of expediency", los cuales han sido subdivididos en 6 categorías conteniendo tres raspadores (piezas ํ215: ำ74, nำ221 y n215/1: nำ73), un yunque (pieza n²18) y cuatro tipos definidos por la forma del mango, denominados por Cruxent como: "Hand-held implements with straight butts" (conformado por las piezas n223/2; n²14/4); "Hafted implements with horizontal handle" (piezas no 229/3; 229/1); "Hand-held instruments with reduced butts" (piezas n229/5; n219/2; n215/2: nำ75) y "Hafted instruments of hand-axe form” (pieza no005) (Cruxent, 1979: 8384). También, posibles artefactos de hueso con modificación (piezas nำ15/3; n215/4; n²14/6; n²14/7; no214/8) son tentativamente registrados como instrumentos añadiendo que estas presentan huellas de uso y/o modificaciones, finalmente refiere un femur usado como yunque (pieza 214/1), el cual según el autor pudo haberse empleado para el proceso de descarnado (Cruxent 1979: 85-87). No queda más que expresar que la presente publicación de Taima-Taima carece de ilustraciones técnicas de los artefactos liticos analizados y ya el editor dispensa la carencia de los mismos (Cruxent 1979: 77). Con este trabajo queda claro la asociación temporal de los artefactos de la serie Joboide a fauna pleistocénica, llevando a pensar lógicamente que el desarrollo de la zona norcentral de Venezuela se ha efectuado de manera independientemente y anterior al complejo Clovis de Norteamérica, pero no queda aclarado el argumento de que esta sea una tecnología diferenciada (Bryan 1973: 245-254; 1975: 151-159 ; Politis 1991: 293).

Al suroeste del estado de Lara se localiza el yacimiento El Vano. En este lugar se ha puesto al descubierto restos óseos de megaterio (Eramotherium rusconni). El estudio de los restos óseos pone en evidencia huellas de corte y fractura, asociado con el descarnado y desmembramiento animal por actividad humana (Quero 2003: 46-64). Estas evidencias aunadas con el descubrimiento en Taima-Taima, ponen de manifiesto una posible actividad de caza especializada en lugares pantanosos de la región.

Entre 1984 y 1985, se han realizado estudios geocronológicos en la cuenca de El Jobo, Valle del río Pedregal, con el fin de comprobar si los cuatro complejos sucesivos asociados a una serie de ocupaciones humanas propuestos por Cruxent son valederos (Oliver \& Alexander, 2003). Tenemos que aclarar que nos ha sido imposible poder consultar el manuscrito en inglés presentado en la reunión Cumbre 89, organizada por el Center for the Study of the First Americans, celebrado en la Universidad de Maine, Orono, EE.UU. Asimismo, el texto que abordaremos se trata de una traducción al español y como los autores mencionan: “[...] hasta cierto punto, modificado y ampliado [...]" (Oliver y Alexander 2003: 85; el subrayado es nuestro).

Como hemos dicho los autores desarrollan sus investigaciones entre 1984-1985 en la cuenca media del río Pedregal, efectuando análisis y sondeo de suelos (análisis de sedimentos aluviales del complejo de terrazas I, II y III), difracción de rayos-X sobre rocas/grava, tectónica y fechados absolutos en relación a un control de variables geológicas y geomorfológicas locales. Con esto les permiten distinguir al menos una secuencia de tres pares de terrazas o superficies fluviales de distintas edades en la cuenca de El Jobo, asimismo denotan y explican la presencia de terrazas huérfanas, erosión de terrazas, plegamientos y la transformación de una vega inundable en una terraza aluvial. Además, es interesante acotar que en el estudio de la vegetación, clima y ambiente se aborda el tema de fracturas naturales en los peñones de cuarcita debido a causas térmicas (Oliver \& Alexander 2003: 130-173). Al explicar la formación de la terraza I y la presencia de los niveles I, IA y IB, se deja abierta la posibilidad que al menos las superficies aluviales denominadas como IB, II, y III ya estaban accesibles a los grupos paleoindios (Oliver \& Alexander 2003: 179).

Con respecto a los sitios arqueológicos localizados en los alrededores de El Camare, mencionan a Peñasquito (CX-1010), La Pelona (CX-1009) y Cerro de Fidel (CX-1157). Si bien se abordan algunas des- 
cripciones del material lítico y hasta se define preliminarmente al sitio el Peñasquito como un área de cantera para la extracción de materia prima.

En otro sitio denominado como Piedra de Chispa (CX-342), se ha podido identificar los talleres con números consecutivos desde el $\mathrm{T} 1$ al T7. Pero es en el taller T1 donde se brinda detalles de la alteración por causas naturales del material arqueológico que en un inicio se disponía de forma circular sobre el terreno, cambiando su disposición debido a la exposición prolongada de lluvias en la zona, sufriendo el material antrópico un desplazamiento vertical por erosión llegando en muchos casos a su desaparición debido al movimiento de gravas, como también se ha registrado el afloramiento en superficie de nuevos talleres (Ibídem: 198-200). Nos parece muy interesante este tipo de datos pues creemos que los sitios de donde procede esta colección que abordaremos en este estudio pueden haber desaparecido.

Un dato fundamental de esta investigación es la identificación de la tradición Joboide en los alrededores de Coro, en el valle del río Eroíta y en los alrededores del Llano de Villa Bolivia. Se reporta también otros sitios de importancia en asociación a puntas de proyectil tipo El Jobo que fueron descubiertos por Cruxent en la cuenca del río Pecaya, al suroeste del Valle de Quibor, Las Tres Cruces en la sierra de Baragua y finalmente hacia el estado de Lara. Asimismo, los autores mencionan la presencia Joboide en la península de Paraguaná. Con estos datos los autores proponen que el tallador Joboide no es propenso a desplazarse más allá de esta área geográfica, empero mantienen abierto el posible desplazamiento de este mismo grupo humano a otros entornos geográficos y que por condiciones inciertas abandonan muy posible la tecnología Joboide remplazándola por otra (Ibídem: 203-205).

Las evidencias de las diversas tradiciones líticas paleoindias halladas en la península de Paraguaná y su geología resultan interesantes en el reporte de Oliver y Alexander (2003). Refiriéndose al material lítico y a los sitios arqueológicos, los autores reportan una serie de puntas similares a las Clovis de Norteamérica en el sitio El Cayude, seguido de puntas del tipo Cola de Pescado, otras que guardan semejanza a las puntas del tipo Dalton norteamericano y finalmente se suma la presencia de piezas líticas del tipo El Jobo y Las Casitas. Al referirse sobre la litología del lugar se hace mención a la presencia de una gran variedad de materias primas. En Paraguaná se registra el empleo de artefactos elaborados sobre chert, calcedonia, cuarzo cristalino, cuarzo lechoso, pizarras, esquistos y gabro, que fueron encontrados y asociados en tierra firme en la Unidad I inferior en el sitio de Taima-Taima (Ibídem: 210-214).

Explican también que los sitios arqueológicos paleoindios reconocidos en Paraguaná, por Cruxent y Gallagher entre 1970 a 1981 suman un total de diez, los cuales guardan estrecha relación con los materiales liticos encontrados en la cuenca de El Jobo. Sin embargo, en otros sitios e.g. Pilancón, Bariana, Misaray, Las Cruces 1-2 y 3, localizados en las cercanías de Cerro Santa Ana, se menciona la presencia de artefactos líticos (bifaces, raspadores, choppers y puntas de proyectil). Los tipos de materia prima que se reportan en estos yacimientos son el gabro y rocas ígneas que afloran en los alrededores de Santa Ana. Otros yacimientos contiguos se localizan en Cerritos y hacia el Norte de Santa Ana, cerca a Mesa de San José de Cocodite, se reportan áreas de cantera y manufactura de artefactos del tipo El Jobo y Las Casitas sobre piedras de cuarzo lechoso, cuarzo traslucido y hasta cuarzo cristalino, (Ibídem: 215-218).

Finalmente, el interesante hallazgo de marcadores temporales en la península de Paraguaná se evidencian con la presencia de puntas del tipo Cola de Pescado, puntas Clovis, Folsom y Sandia en el sitio El Cayude (sitios № 104 y № 106) (Szabadics 1997: 104-105: fotos 57-60; 111-114). Estos fueron reconocidos en la colección lítica donada por Miklos Szabadics a la Universidad Francisco de Miranda y posteriormente revisadas por Oliver (oliver \& Alexander 2003: 218-19). Al menos dos fotografías, la primera de una punta de proyectil sin acanaladura confeccionado según los autores sobre chert y dos Puntas Cola de Pescado confeccionados sobre un chert de tonos amarillos y blancos y otro sobre cuarcita arenisca del sitio El Cayude (№ 106) fueron expuestas en la publicación (Oliver \& Alexander 2003: 211, figuras 64 y 65). Una serie de datos concernientes a la materia prima y a la presencia de material lítico del tipo Joboide en la península de Paraguaná han sido ya mencionadas (Szabadics 1997: 106: foto № 62; 108: foto № 65), dejando como tema de discusión la posible contemporaneidad o discordancia temporal entre las 
evidencias de puntas Clovis, Cola de Pescado y Joboides, asimismo se deja abierto el tema de su arribo o ruta de migración desde el istmo de Panamá hacia la península de Paraguaná.

\section{ANÁlisis Petrográfico del material lítico de tipología joboide de Paraguaná}

Los materiales líticos arqueológicos han sido analizados con una lupa de 10X a 20X de aumento. El análisis petrográfico ha determinado que la arenisca cuarzosa empaquetada ha sido la materia prima seleccionada para la elaboración de artefactos (100\%). Se trata de una roca metamórfica, de colores marrón $(55,5 \%)$, gris $(37,3 \%)$ y granate $(7,4 \%)$. El grado de silicificación es alto, llegando a un $90 \%$ lo cual le confiere la solidez y fractura concoidea de buena calidad. La presencia de diaclasas de cuarzo no ha sido impedimento para la formación y finalización de piezas líticas. En la tabla 1, se detalla la cantidad de piezas arqueológicas con los números de inventario catalogados por yacimientos, color, tipo de roca y dureza.

Tabla 1. Análisis petrográfico del material lítico de la península de Paraguaná

\begin{tabular}{|c|c|c|c|c|}
\hline № Pieza & Yacimiento & Color & Tipo Roca & Dureza (Mohos) \\
\hline L-0022 & \multirow{4}{*}{ CX405 } & Granate & \multirow{4}{*}{$\begin{array}{c}\text { Arenisca cuarzosa } \\
\text { empaquetada }\end{array}$} & \multirow{4}{*}{$2-2,5$} \\
\hline L-0024 & & Gris & & \\
\hline L-0021 & & Marrón & & \\
\hline L-0026 & & Marrón & & \\
\hline L-0023 & \multirow{3}{*}{ CX433 } & Marrón & \multirow{3}{*}{$\begin{array}{c}\text { Arenisca cuarzosa } \\
\text { empaquetada }\end{array}$} & \multirow{3}{*}{$2-2,5$} \\
\hline L-0025 & & Marrón & & \\
\hline L-0027 & & Marrón & & \\
\hline L-0014 & \multirow{8}{*}{ CX658 } & Gris & \multirow{8}{*}{$\begin{array}{c}\text { Arenisca cuarzosa } \\
\text { empaquetada }\end{array}$} & \multirow{8}{*}{$2-2,5$} \\
\hline L-0016 & & Gris & & \\
\hline L-0017 & & Marrón & & \\
\hline L-0018 & & Gris & & \\
\hline L-0019 & & Marrón & & \\
\hline L-0020 & & Gris & & \\
\hline L-0015 & & Gris & & \\
\hline L-0013 & & Gris & & \\
\hline L-0001 & \multirow{5}{*}{ CX903 } & \multirow{5}{*}{ Marrón } & \multirow{5}{*}{$\begin{array}{c}\text { Arenisca cuarzosa } \\
\text { empaquetada }\end{array}$} & \multirow{5}{*}{$2-2,5$} \\
\hline L-0002 & & & & \\
\hline L-0003 & & & & \\
\hline L-0004 & & & & \\
\hline L-0005 & & & & \\
\hline L-0006 & CX943 & Gris & $\begin{array}{c}\text { Arenisca cuarzosa } \\
\text { empaquetada }\end{array}$ & $2-2,5$ \\
\hline L-0008 & \multirow{6}{*}{ CX945 } & Gris & \multirow{6}{*}{$\begin{array}{c}\text { Arenisca cuarzosa } \\
\text { empaquetada }\end{array}$} & \multirow{6}{*}{$2-2.5$} \\
\hline L-0009 & & Marrón & & \\
\hline L-0010 & & Marrón & & \\
\hline L-0011 & & Granate & & \\
\hline L-0012 & & Gris & & \\
\hline L-0007 & & Marrón & & \\
\hline
\end{tabular}




\section{Tipología líticA DEL MATERIAL LÍTICo}

El criterio técnico y morfológico ha sido empleado para la elaboración de la tipología del material lítico procedente de la península de Paraguaná (Querol et al. 1978: 14; Koslowsky et al. 1974: 20). Además, se ha hecho empleo de manuales para las definiciones de los útiles (Merino 1994; Inizan et al. 1995; Piel-Desruisseax 1989) y de las listas tipológicas clásicas europeas del paleolítico inferior y medio (Bordes 1981; Sonneville-Bordes et al. 1956). La tipología lítica se clasifica en la tabla 2.

\subsection{DEFINICIÓN TIPOLÓGICA}

\section{A. Útiles bifaciales y preformas}

Los útiles bifaciales están compuestos por preformas que concuerdan con las registradas para el complejo El Jobo. Asimismo, fragmentos de puntas foliáceas, conforman este tipo.

Tabla 2. Tipología preliminar del material lítico de Paraguaná

\begin{tabular}{|c|c|c|c|}
\hline Grupo & Tipología & Cantidad & $\%$ \\
\hline \multicolumn{4}{|c|}{ A. Útiles bifaciales } \\
\hline A.1 & Preforma de bifaz & 7 & $25,9 \%$ \\
\hline A. 2 & Fragmento Mesial de punta bifacial & 5 & $18,5 \%$ \\
\hline A. 3 & Fragmento Meso-Apical de punta bifacial & 6 & $22,2 \%$ \\
\hline A.4 & Fragmento basal de punta bifacial & 2 & $7,4 \%$ \\
\hline \multicolumn{4}{|c|}{ B. Útiles Ordinarios } \\
\hline B.1.1 & Punta Unifacial & 1 & $3,7 \%$ \\
\hline \multicolumn{4}{|c|}{ B.2 Útil a posteriori } \\
\hline B.2.1 & LSPD modificada a posteriori & 2 & $7,4 \%$ \\
\hline \multicolumn{4}{|c|}{ B.3 Raspadores } \\
\hline B.3.1 & Raspador Simple & 1 & $3,7 \%$ \\
\hline B.3.2 & Raspador lateral & 1 & $3,7 \%$ \\
\hline \multicolumn{4}{|c|}{ C. Desecho } \\
\hline C. 1 & Desecho de talla & 2 & $7,4 \%$ \\
\hline \multicolumn{2}{|r|}{ Total piezas líticas } & 27 & $100 \%$ \\
\hline
\end{tabular}

\section{A.1 Preforma de bifaz}

Se trata de piezas burdas y gruesas que presentan inicio de reducción por percusión dura y en algunos casos con presencia de córtex. Su recurrencia es la más alta $(25,9 \%)$ y corresponden netamente a la tipología joboide. Concuerdan con un estadio inicial de talla en donde los blanks seleccionados son rocas de naturaleza muy posible angulosa y/o guijas. La reducción alterna ha sido la predilecta para su reducción, observándose sobre su superficie negativos netamente amplios y profundos.

\section{A.2 Fragmento mesial de punta bifacial}

Se define este tipo por la presencia de piezas incompletas e identificadas como partes mesiales de piezas bifaciales finalizadas (18,5\%). A juzgar por sus secciones biconvexas, siluetas lanceoladas, sus vistas laterales de forma paralelos rectos y reducción tecnológica muy posible por percusión blanda confirman su fase avanzada de talla. 


\section{A.3 Fragmento meso apical de punta bifacial}

Se trata de piezas fragmentadas identificadas como meso apicales de puntas reducidas muy posible por percusión blanda y eventualmente percusión dura. Sus siluetas son triangulares, vistas laterales de forma paralelos rectos y secciones biconvexas las delatan como piezas de talla avanzada y en algunos caso de finalización.

\section{A.4 Fragmento basal de punta bifacial}

Al menos dos piezas $(7,4 \%)$ han sido identificadas en este tipo. A juzgar por sus formas se les asocia con la parte basal de piezas bifaciales. No tienen presencia de córtex. Una fractura transversal tecnológica con terminación en lengüeta es observada sobre el tercio inferior de la pieza. Al menos una de estas presenta negativos profundos y con evidencia de reducción alterna.

\section{B. Útiles Ordinarios}

\section{B.1.1 Punta Unifacial}

Se trata de una pieza unifacial (3,7\%) sobre un fragmento de lasca laminar de forma rectangular alargada, tallada por percusión dura, o blanda, y que necesariamente presenta retoque a presión en los bordes. Se trata de una punta con trabajo unifacial finalizada.

\section{B.2 Útil a posteriori (UP)}

Se trata de piezas líticas que presentan pequeños retoques irregulares continuos tanto inversa como cruzada, localizándose generalmente en los bordes de las lascas; estos pueden ser originados debido a producto antrópico, natural, o posiblemente por uso (Bordes 1981: 67). Las siglas UP significan Útil a posteriori.

\section{B.2.1 LSPD modificada a posteriori (LSPD UP)}

Lasca secundaria a percusión dura, que posee en uno o más de sus bordes, incluido en el extremo distal, desprendimientos a posteriori. Su presencia es de un $7,4 \%$.

\section{B.3 Raspadores}

Lascas que muestran en una o dos extremidades un retoque continuo, no abrupto, que determina un frente mas o menos redondeado o parabólico, rara vez rectilíneo, y más raro aún cóncavo (Merino 1994: 67; Piel-Desruisseaux 1989: 92; Sonneville-Bordes et al. 1956). Esta presenta variantes definidas por la tipología clásica, que a continuación se detalla:

\section{B.3.1 Raspador simple}

Lascas o fragmentos de lascas que muestran retoque a lo largo del borde o periferia de la pieza. A pesar de su poca presencia $(3,7 \%)$ se trata de un tipo bien definido.

\section{B.3.2 Raspador lateral}

Elaborado sobre una lasca, el retoque presenta una delineación convexa sobre su lado derecho. Si bien su presencia es en baja proporción (3,7\%), se trata de una pieza bien definida.

\section{Desecho de talla}

Lo conforma el 7,4\% del material documentado. Presenta gran potencial para los análisis tecnológicos. En cuanto ha sido posible, se ha tratado de determinar la procedencia del desecho. En vista de su 
poca recurrencia hemos decidido solo crear de manera general este ítem. Sin embargo, hemos identificado muy posible un desecho de núcleo y desecho de útil.

\section{El Yacimiento CX405}

\subsection{UBICACIÓN}

Sur-Oeste del cerro Santa Ana. península de Paraguaná.

\subsection{TIPOLOGÍA}

\begin{tabular}{|c|c|c|c|c|}
\hline \multicolumn{5}{|c|}{ Tecno tipología lítica del sitio CX405 } \\
\hline \multicolumn{2}{|c|}{ Grupo } & Tipo & № & $\%$ \\
\hline \multirow{2}{*}{ 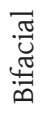 } & A. 2 & Fragmento mesial de punta bifacial. & 1 & $25 \%$ \\
\hline & A.3 & Fragmento meso apical de punta bifacial & 1 & $25 \%$ \\
\hline \multirow{2}{*}{ 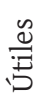 } & B2.1 & Lasca secundaria a percusión dura modificada a posteriori & 1 & $25 \%$ \\
\hline & B3.1 & Raspador simple & 1 & $25 \%$ \\
\hline \multicolumn{3}{|c|}{ Total piezas líticas antrópicas } & 4 & $100 \%$ \\
\hline
\end{tabular}

\subsection{OBSERVACIÓN A LOS MATERIALES LÍTICOS Y TIPOLOGÍA}

El útil determinado como la lasca secundaria a percusión dura modificada con código de inventario L-0026 del grupo B2.1 (Fig. 1), tiene una longitud de $46 \mathrm{~mm}$, ancho de $32 \mathrm{~mm}$ y espesor de $8 \mathrm{~mm}$. Esta puede indicarnos muy posible evidencia de talla bifacial en el sitio. Sobre la dorsal de la pieza se pueden observar dos negativos paralelos y una nervadura central las cuales delatan su soporte, siendo éste un posible blank pseudo laminar. El tipo de talón es puntiforme y terminación distal en pluma, lo cual la calificamos como una lasca exitosa. Su peso de 8,30 gr sin presencia de córtex, el ángulo de expulsión es de $75^{\circ}$ y su vista lateral de forma cóncava convexa evidencian al menos la actividad de talla bifacial. Las modificaciones a posteriori se localiza en la periferia de la pieza, se delinean de forma paralela irregular, posición cruzada y distribución continua. Los bordes modificados con ángulos agudos entre $30^{\circ}$ y $40^{\circ}$ pueden sugerir su uso muy posible frente a materiales blandos.

El útil L-0021 del grupo B3.1, tipológicamente definida como un raspador simple (Fig. 2), a juzgar por su forma puede ser definida como un útil compuesto (raspador-perforador). Empero, la presencia de perforadores es nula en la colección. Sus medidas son de $41 \mathrm{~mm}$ de longitud, ancho de $27 \mathrm{~mm}$ y espesor $13 \mathrm{~mm}$. Su peso es de 13,98 gr. Su silueta es triangular irregular, lateral y sección presentan formas trapezoidales. No hay presencia de córtex y el blank seleccionado para su confección ha sido una lasca relativamente gruesa, de talla bifacial y de puesta en forma. El ángulo de borde activo tiene un rango entre $65^{\circ}$ y $80^{\circ}$. El retoque es cóncavo convexo y de extensión corta, inclinación entre semiabrupta a abrupta localizando en toda la periferia de la pieza, finalmente su posición es unifacial distribuyéndose de forma continua.

Dos fragmentos de piezas bifaciales pertenecen al grupo A.2 (L-0024) y al grupo A.3 (L-0022). Ambas presentan fracturas transversales de tecnológica en lengüeta. Estas fracturas muy posibles fueron originadas en la fase final de talla. El ángulo de borde bifacial en ambas piezas es de $70^{\circ}$ y el empleo de percusión blanda es la más posible.

La pieza L-0022 (A.3), tiene una longitud de $31 \mathrm{~mm}$, ancho de $21 \mathrm{~mm}$ y espesor de $9 \mathrm{~mm}$. Su peso es de 5,14 gr. Su vista frontal y lateral es de forma triangular y su sección presenta forma biconvexa. 
Por el contrario, en la pieza L-0024 (A.2) estamos frente a un fragmento mesial de bifaz y presenta dos fracturas transversales de origen tecnológico. Tiene una longitud de $32 \mathrm{~mm}$, ancho $18 \mathrm{~mm}$, espesor de $10 \mathrm{~mm}$ y peso de 7,79 gr. Su silueta es rectangular, lateral paralelos rectos y sección biconvexa.

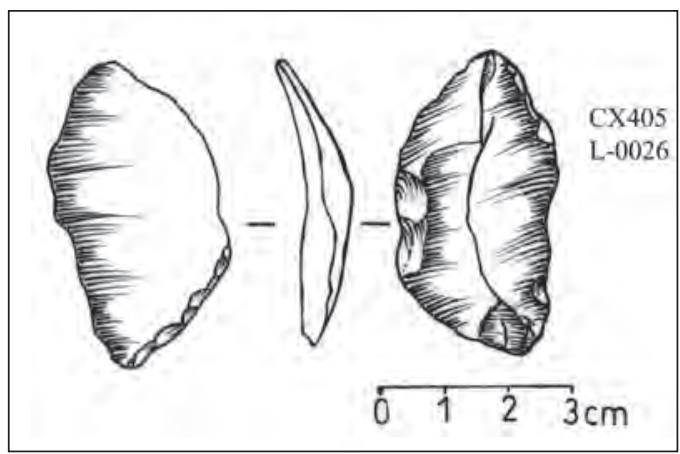

Figura 1. Lasca secundaria a percusión dura modificada.

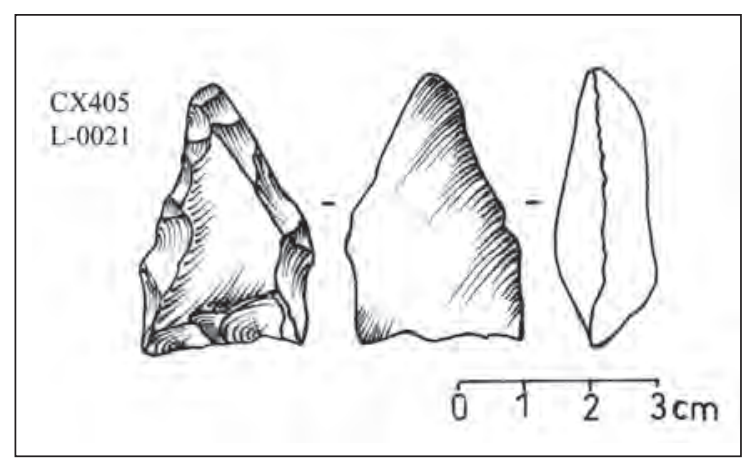

Figura 2. Raspador simple.

\section{Cadena Operativa}

Se cuenta con dos fragmentos bifaciales y dos útiles. Con respecto a la materia prima, tenemos que mencionar que la selección predilecta ha sido la arenisca cuarzosa empaquetada de coloración gris a marrón claro. La uniformidad del tipo de roca puede demostrar que la selección de ésta ha sido para la confección de piezas bifaciales. Su dureza entre 2 y 2,5 en la escala de mohs hace pesar que su empleo ha sido muy posible para modificar materiales blandos. Se suma la evidencia de una lasca pseudo laminar L-0026, en esta llama la atención la modificación que se observa en sus bordes, de ángulos agudos, ya puede evidenciar que junto al raspador lateral L-0021, muy posible actividades sobre material blando.

\section{El Yacimiento CX433}

\subsection{UBICACIÓN}

Sur-Oeste del cerro Santa Ana, península de Paraguaná

\subsection{TIPOLOGÍA}

\begin{tabular}{|c|c|l|c|c|}
\hline \multicolumn{5}{|c|}{ Tecno tipología lítica del sitio CX433 } \\
\hline \multicolumn{2}{|c|}{ Grupo } & \multicolumn{1}{|c|}{ Tipo } & № & $\%$ \\
\hline \multirow{2}{*}{ Bifacial } & A.1 & Preforma de Bifaz & 1 & $33,3 \%$ \\
\cline { 2 - 5 } & A.2 & Fragmento mesial punta bifacial & 1 & $33,3 \%$ \\
\hline Útil & B3.2 & Raspador lateral & 1 & $33,3 \%$ \\
\hline \multicolumn{2}{|c|}{ Total de piezas líticas antrópicas } & 3 & $100 \%$ \\
\hline
\end{tabular}

\subsection{OBSERVACIÓN A LOS MATERIALES LÍTICOS Y TIPOLOGÍA}

Dos piezas bifaciales y un útil conforman los materiales de este yacimiento.

Con respecto a la preforma de bifaz del grupo A.1 y con rótulo L-0023 (Fig. 3), se trata de una preforma de punta bifacial que tiene una longitud de $50 \mathrm{~mm}$, ancho de $19 \mathrm{~mm}$, espesor de $15 \mathrm{~mm}$ y peso de 11,45 gr. Sus superficies, tanto superior como inferior, la delatan como una pieza en proceso de ta- 
lla pues presenta negativos profundos y nervaduras bien marcadas. Empero a juzgar por su tamaño y peso podría tratarse de una pieza fallida y abandonada. Su silueta es lanceolada, la forma lateral y sección es biconvexa. Presenta reducción alterna haciendo empleo de percutor duro. El ángulo de borde bifacial fluctúa entre $75^{\circ}$ y $80^{\circ}$. No hay presencia de córtex por lo que su fase de talla es avanzada.

Un fragmento mesial también de una punta bifacial L-0025 del grupo A.2 ha sido determinada. No hay presencia de córtex, presenta un peso de 18,03gr, longitud de $46 \mathrm{~mm}$, ancho de $28 \mathrm{~mm}$ y espesor de $12 \mathrm{~mm}$. El ángulo de borde bifacial se ha determinado entre $65^{\circ} \mathrm{y} 70^{\circ}$. Su vista lateral indica simetría entre sus superficies superior e inferior. La tecnología empleada ha sido la percusión blanda y eventualmente percusión dura. Las fracturas son debidas a causa tecnológica con presencia de lengüetas. Se trata de una pieza en fase final de talla.

El raspador lateral L-0027 del grupo B3.2 (Fig. 4), permite al menos identificar su soporte sobre una lasca secundaria a percusión dura. El blank de lasca permite interpretar la selección de un fragmento de lasca gruesa para su posterior confección. Su longitud es de $68 \mathrm{~mm}$, ancho de $25 \mathrm{~mm}$, espesor de $14 \mathrm{~mm}$ y peso de 23,45 gr. La silueta de la pieza es rectangular, su vista lateral es recto paralela y sección triangular. La reducción ha sido empleando percusión dura. La delineación del retoque es convexa, extensión corta localizándose en uno de los bordes lateral derecho de la lasca, su morfología es irregular posición unifacial y distribución continua.

\section{Cadena Operativa}

La materia prima seleccionada para la confección de estos artefactos ha sido la arenisca cuarzosa empaquetada. Al menos la preforma de bifaz reducida a percutor duro conjuntamente con el fragmento mesial de punta en fase final de talla, pueden indicarnos que la fabricación de bifaces puede estar efectuándose in situ. El uso de lascas en la fabricación de los raspadores de morfología gruesa y burda parece ser la predilecta. No tenemos más desecho que indiquen mayores indicios sobre los trabajos efectuados en este yacimiento.

\section{El YACIMIENTO CX658 \\ 8.1 UBICACIÓN}

Suroeste del cerro Santa Ana. Península de Paraguaná.

\subsection{TIPOLOGÍA}

\begin{tabular}{|c|c|l|c|c|}
\hline \multicolumn{5}{|c|}{ Tecno tipología lítica del sitio CX658 } \\
\hline \multirow{3}{*}{ Grupo } & \multicolumn{1}{|c|}{ Tipo } & № & $\%$ \\
\hline \multirow{3}{*}{ Bifacial } & A.1 & Preforma de Bifaz & 1 & $12,5 \%$ \\
\cline { 2 - 5 } & A.2 & Fragmento mesial punta bifacial & 1 & $12,5 \%$ \\
\cline { 2 - 5 } & A.3 & Fragmento meso apical de punta bifacial & 2 & $25 \%$ \\
\cline { 2 - 5 } & A.4 & Fragmento basal de punta bifacial & 1 & $12,5 \%$ \\
\hline Unifaz & B1.1 & Punta unifacial & 1 & $12,5 \%$ \\
\hline Desecho de talla & C & Desecho de talla & 2 & $25 \%$ \\
\hline \multicolumn{2}{|c|}{ Total de piezas líticas antrópicas } & 3 & $100 \%$ \\
\hline
\end{tabular}

\subsection{OBSERVACIÓN A LOS MATERIALES LÍTICOS Y TIPOLOGÍA}

El material arqueológico de este yacimiento está conformado por la presencia de cinco fragmentos bifaciales una punta unifacial y dos desechos de talla. 


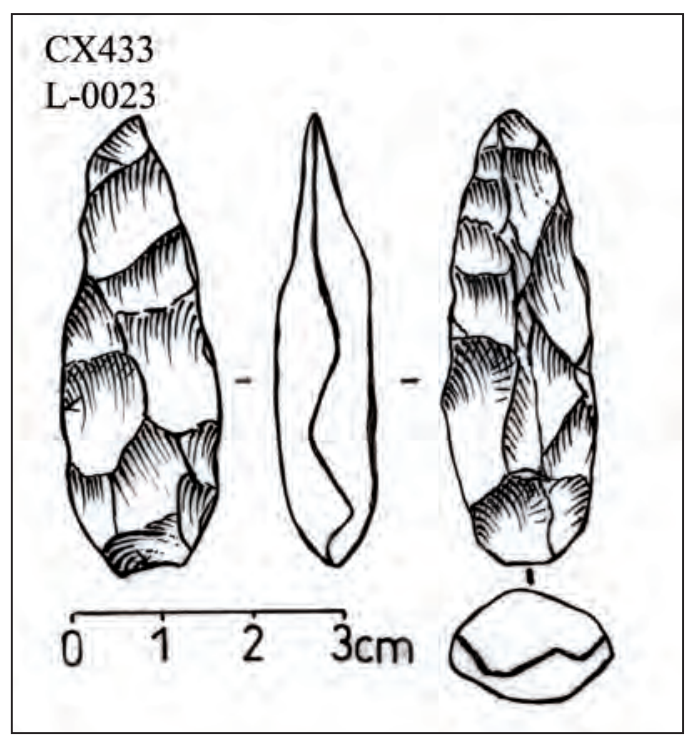

Figura 3. Preforma de bifaz. península de Paraguaná. Colección de José María Cruxent.

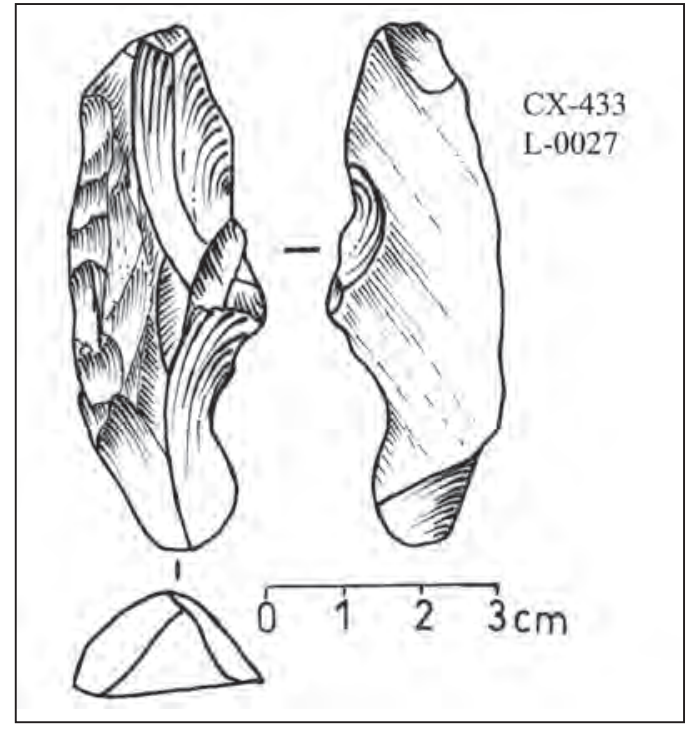

Figura 4. Raspador lateral sobre lasca. península de Paraguaná. Colección de José María Cruxent.

Una preforma de bifaz L-0019, grupo A.1, se encuentra fracturada en uno de sus bordes por causas tecnológicas (Fig. 5). No tiene presencia de córtex, y la reducción centrípeta por talla alterna ha sido empleada sobre esta pieza. Dos diaclasas de cuarzo se localizan en los bordes laterales de la pieza, haciéndola inestable para la talla. Sus medidas son longitud de $99 \mathrm{~mm}$, ancho $90 \mathrm{~mm}$, espesor de 39 $\mathrm{mm}$ y peso de 317,36 gr la delatan como una pieza en fase posterior al decorticado. Siendo aún gruesa y burda, el ángulo de borde activo varía entre $75^{\circ}$ y $80^{\circ}$. La tecnología empleada durante su reducción ha sido la percusión dura. Su silueta de forma rectangular, lateral biconvexo irregular y sección trapezoidal hacen pensar en la selección de un blank con bordes angulosos, muy posible de forma tetraédrica. Se trata de una pieza en fase posterior al decorticado y/o inicio de puesta en forma.

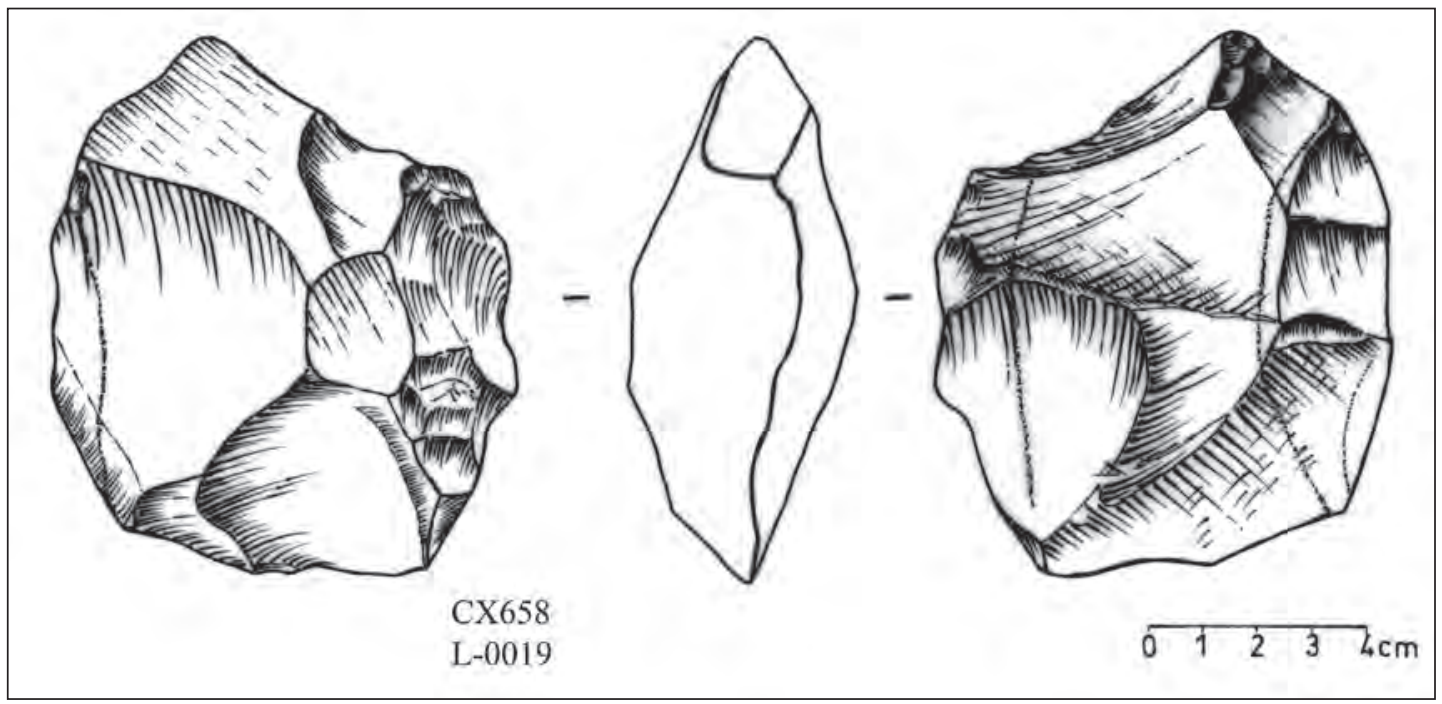

Figura 5. Preforma de bifaz. península de Paraguaná. Colección de José María Cruxent. 
La pieza L-0018 es un fragmento mesial de punta bifacial del grupo A.2. Confeccionada muy posible sobre una lasca alargada (laminar), tiene una longitud de $42 \mathrm{~mm}$, ancho $29 \mathrm{~mm}$, espesor de $9 \mathrm{~mm}$ y peso de 12,43 gr. El ángulo de borde bifacial fluctúa entre $50^{\circ}$ y $55^{\circ}$. La tecnología empleada ha sido la percusión dura en ambas facetas. La vista en perfil de sus bordes laterales delata la sinuosidad provocada por reducción alterna. La no presencia de córtex, el grosor de la pieza y la forma biconvexa de su vista en sección y paralelo recto en perfil evidencian su fase avanzada de talla. Dos fracturas transversales localizadas en el tercio superior y tercio inferior parecen estar asociadas a causas naturales.

Dos piezas del grupo A.3, han sido de terminadas como fragmentos meso apicales de puntas bifaciales. La pieza L-0016, presenta una fractura tecnológica clara. Su longitud es de $58 \mathrm{~mm}$, ancho de 25 $\mathrm{mm}$, espesor $12 \mathrm{~mm}$ y peso específico de 13,30 gr el ángulo de borde activo bifacial varía entre $65^{\circ} \mathrm{a}$ $70^{\circ}$. Imperfecciones en la roca son observadas notándose una diaclasa en uno de los bordes laterales. La silueta es triangular, su lateralidad es de forma paralela recta y sección biconvexa. La tecnología aplicada ha sido la percusión dura y eventualmente reducida por percutor blando. Aún se observa en sus bordes la típica reducción alterna de piezas bifaciales. El eje de simetría aún es relativamente burdo por lo que se trata de una pieza que está siendo regularizada y de fase avanzada de talla.

La pieza L-0017 ha sufrido una fractura natural debido a una diaclasa que contiene impurezas posiblemente de oxido. El color de la pieza es un marrón claro. Su longitud es de $80 \mathrm{~mm}$, ancho $36 \mathrm{~mm}$ y espesor de $14 \mathrm{~mm}$. Su peso es de 31,76 gr. No tiene presencia de córtex y el ángulo de borde activo bifacial varía entre $55^{\circ}$ y $60^{\circ}$. La tecnología empleada ha sido la percusión dura y eventualmente percusión con percutor blando. Esta pieza se encuentra muy bien delineada lo cual hace pensar en etapas de finales de talla.

El grupo A.4, un fragmento basal de pieza bifacial con rótulo L-0014, tiene un peso de 12,68 gr. Presenta una fractura transversal tecnológica. Ha sido reducida por percusión blanda. El blank ha sido muy posible una lasca alargada y gruesa. Sus medidas son $59 \mathrm{~mm}$ de longitud, $18 \mathrm{~mm}$ de ancho y $11 \mathrm{~mm}$ de ancho. Se trata de una pieza delgada y en fase final de talla. Su sección biconvexa y lateral paralelo recto indican que se trata de una pieza con buen eje de equilibrio. La delineación del retoque es cóncavo convexo, extensión corta, inclinación abrupta localizándose en la periferia de la pieza. La morfología de los retoques es paralela irregular, siendo su posición bifacial y distribución continua.

La punta unifacial del grupo B1.1 y con número de catálogo L-0020 ha sido obtenida a partir de una lasca secundaria a percusión dura laminar (Fig. 6). La pieza no se muestra completa, teniendo en la parte proximal de la lasca y/o basal del artefacto una fractura transversal en lengüeta debido a causas tecnológicas. La longitud de la pieza es de $116 \mathrm{~mm}$, ancho de $38 \mathrm{~mm}$ y espesor de $19 \mathrm{~mm}$. El máximo ancho y espesor se localiza en la parte mesial de la punta, su peso es de 77,57 gr. El ángulo de borde activo varía entre $55^{\circ}$ y $70^{\circ}$. La forma de la silueta es lanceolada alargada, el perfil es recto convexo irregular, observándose algunas aristas pronunciadas sobre la faceta dorsal de la pieza. Vista de sección es de forma recto convexa. La tecnología empleada en la faceta dorsal ha sido la percusión dura y eventualmente percusión blanda. No se muestra presencia de córtex. La delineación de los retoques es convexa y presenta una extensión corta, tienen una inclinación semiabrupta, localizándose en el izquierdo y derecho. La morfología de los retoques se muestra de forma paralela irregular y por secciones se torna escamosa, su posición es unifacial y distribución continua.

En el grupo C contamos con dos desechos de talla. La pieza L-0013, bien debe de ser definida como un desecho de útil. Al parecer es sospechosa de ser un desecho de pieza unifacial. Sin embargo, mayores detalles no pueden ser referidos. Presenta una longitud de $69 \mathrm{~mm}$, ancho de $57 \mathrm{~mm}$ y espesor de $25 \mathrm{~mm}$. Su peso específico es de 61,06 gr. Se observa sobre una de sus facetas, una serie de retoques paralelos, de delineación recta convexa, extensión corta, inclinación abrupta, localizándose sobre un segmento del borde del desecho. La pieza L-0015, un desecho de talla pleno, tiene una longitud de 52 $\mathrm{mm}$, ancho de $70 \mathrm{~mm}$, espesor de $23 \mathrm{~mm}$ y peso de 79,71 gr. Su silueta y sección son de forma trapezoidal, perfil cóncavo convexo y sus negativos y nervaduras centrípetas pueden indicarnos que proviene de talla bifacial, muy posible de puesta en forma o fase posterior al decorticado. 


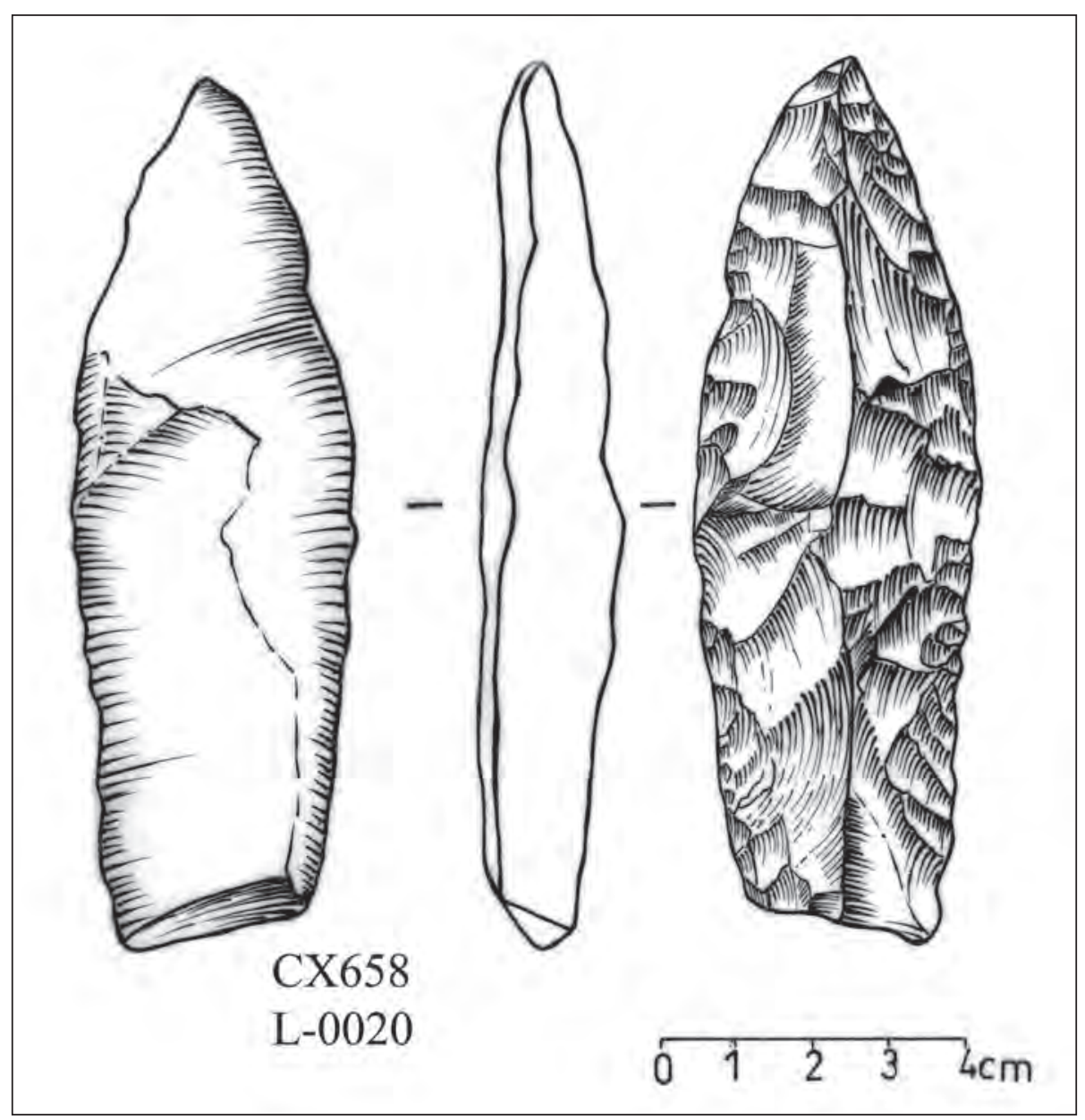

Figura 6. Punta Unifacial. península de Paraguaná. Colección de José María Cruxent.

\section{Cadena Operativa}

La materia prima del yacimiento CX658 ha sido determinada como una arenisca cuarzosa empaquetada. Los colores de las piezas fluctúan desde un gris claro, coloración rojiza y en ocasiones llegando a un marrón claro. La patina en estas piezas es brillosa y su fractura es concoidal de buena calidad. La uniformidad en la selección de la materia prima muy posible con formas tetraédricas para confeccionar piezas bifaciales es lo más probable. Al menos una punta unifacial L-0020 que presenta imperfecciones en su simetría y puntas bifaciales como las piezas L-0014, L-0016, L-0017 y L-0018 sugieren que ha sido la actividad efectuada para obtener este tipo de piezas. La preforma de bifaz L-0019 y dos desechos L-0013 y L-0015, puede reforzar lo dicho anteriormente, evidenciando que se están elaborando muy probable in situ, o al menos las fases finales de talla se realizan en el yacimiento. Asimismo, dos desechos de talla se muestran en clara asociación con la reducción de piezas bifaciales.

\section{El YACIMIENTO CX903}

\subsection{UBICACIÓN}

Cerro Santa Ana. Península de Paraguaná. 


\subsection{TIPOLOGÍA}

\begin{tabular}{|c|c|c|c|c|}
\hline \multicolumn{5}{|c|}{ Tecno tipología del sitio CX903 } \\
\hline Grupo & Tipo & № & $\%$ \\
\hline Bifacial & A.1 & Preforma de bifaz & 5 & $100 \%$ \\
\hline \multicolumn{2}{|c|}{ Total de piezas líticas antrópicas } & 5 & $100 \%$ \\
\hline
\end{tabular}

\subsection{OBSERVACIÓN A LOS MATERIALES LÍTICOS Y TIPOLOGÍA}

Se cuenta con cinco preformas de bifaz determinadas en el grupo tipológico A.1, de las cuales cuatro han sufrido fractura tecnológica. La preforma de bifaz completa L-0001 (Fig. 7), ha sido modificado con percutor de piedra en ambas facetas, las huellas de los negativos son profundos y las nervaduras bien marcadas. La vista frontal de la pieza de forma romboidal irregular, el perfil paralelo irregular y su sección de forma tetraédrica a romboidal nos da indicios del tipo de selección del blank. Asimismo, se suma la presencia de córtex entre un $20 \%$ a $30 \%$ indicando con certeza que el blank seleccionado ha sido un tipo de roca de naturaleza angulosa y que a juzgar por su forma puede haber sido de aspecto tetraédrico. Sus medidas son de longitud de $127 \mathrm{~mm}$, ancho de $75 \mathrm{~mm}$, espesor de $25 \mathrm{~mm}$ y peso 376,68 gr. Su peso es el mayor de toda la colección pudiendo ser las dimensiones reales del blank de $150 \mathrm{x}$ $100 \mathrm{~mm}$ aproximadamente. El ángulo de borde bifacial oscila entre $75^{\circ}$ a $80^{\circ}$ típico en las preformas bifaciales. El empleo de la reducción alterna es evidente en esta pieza.

La preforma L-0004 (Fig. 8) llama la atención por estar modificada sobre una lasca gruesa y burda. Esta presenta una fractura tecnológica en su parte mesial y tiene un peso de 365,7 gr. Su longitud es de $119 \mathrm{~mm}$, ancho 88, espesor de $41 \mathrm{~mm}$. El máximo ancho y espesor se localizan en la parte mesial y justo sobre la fractura transversal de la pieza. El ángulo de borde bifacial es abrupto llegando a medir entre $75^{\circ}$ a $90^{\circ}$. Su forma frontal es trapezoidal irregular, perfil rectangular y sección trapezoidal. La pieza ha sido reducida haciendo empleo de percutor de piedra sobre la cara dorsal de la lasca, observándose sobre ella negativos profundos y nervaduras bien marcadas. Se trata de una pieza burda aún en inicios de desbastado que esta siendo reducida unifacialmente.

La pieza L-0002 (Fig. 9), es una preforma bifacial típica, sus dimensiones son $148 \mathrm{~mm}$ de longitud, ancho de $72 \mathrm{~mm}$ y espesor de $37 \mathrm{~mm}$. El máximo ancho se localiza sobre su parte mesial y el máximo espesor sobre el tercio inferior. Su peso es de 366,68 gr el ángulo de borde bifacial es abrupto, oscilando entre $75^{\circ}$ a $90^{\circ}$. Su silueta es rectangular irregular, vista de perfil sus bordes son paralelos rectos y de sección romboidal irregular. Se ha hecho empleo de la reducción por medio de percusión con percutor duro, hay una pequeña presencia de córtex que puede llegar a ser un $3 \%$ del total de la pieza. Sobre su base se observa una fractura transversal del tipo tecnológico, muy probable este tipo de fracturas se deba al contenido de impurezas de la roca, en este caso se observa una diaclasa en la parte basal de la pieza. La reducción alterna ha sido la típica empleada en su confección.

Otra preforma de bifaz presenta dos fracturas tecnológicas (L-0003: Fig. 10): una localizada en la parte longitudinal sobre el borde lateral; y la otra sobre su parte basal es la pieza. Se trata de una preforma sin córtex, sus dimensiones son de 160 x 68 x $35 \mathrm{~mm}$. Tiene un peso específico de 295,39 gr. El peso indica su fase de puesta en forma, su máximo ancho y espesor se localiza sobre el tercio superior de la pieza y se configura aún con imperfecciones en el eje de equilibro de la pieza. Se observa una diaclasa de cuarzo cruzando de forma transversal sobre el tercio superior de la pieza. El ángulo de borde bifacial es típico de las preformas llegando a oscilar en este caso entre $75^{\circ}$ a $90^{\circ}$. Lo cual es ya recurrente entre las piezas analizadas. Los negativos profundos y amplios así como las nervaduras marcadas y reducción alterna, reflejan el empleo de percusión dura durante su confección.

Estando frente a la pieza L-0005, definido como un fragmento de preforma bifacial de dimensiones pequeñas debido a una fractura transversal plena tiene una longitud de 79 x 77 x $29 \mathrm{~mm}$. Su 


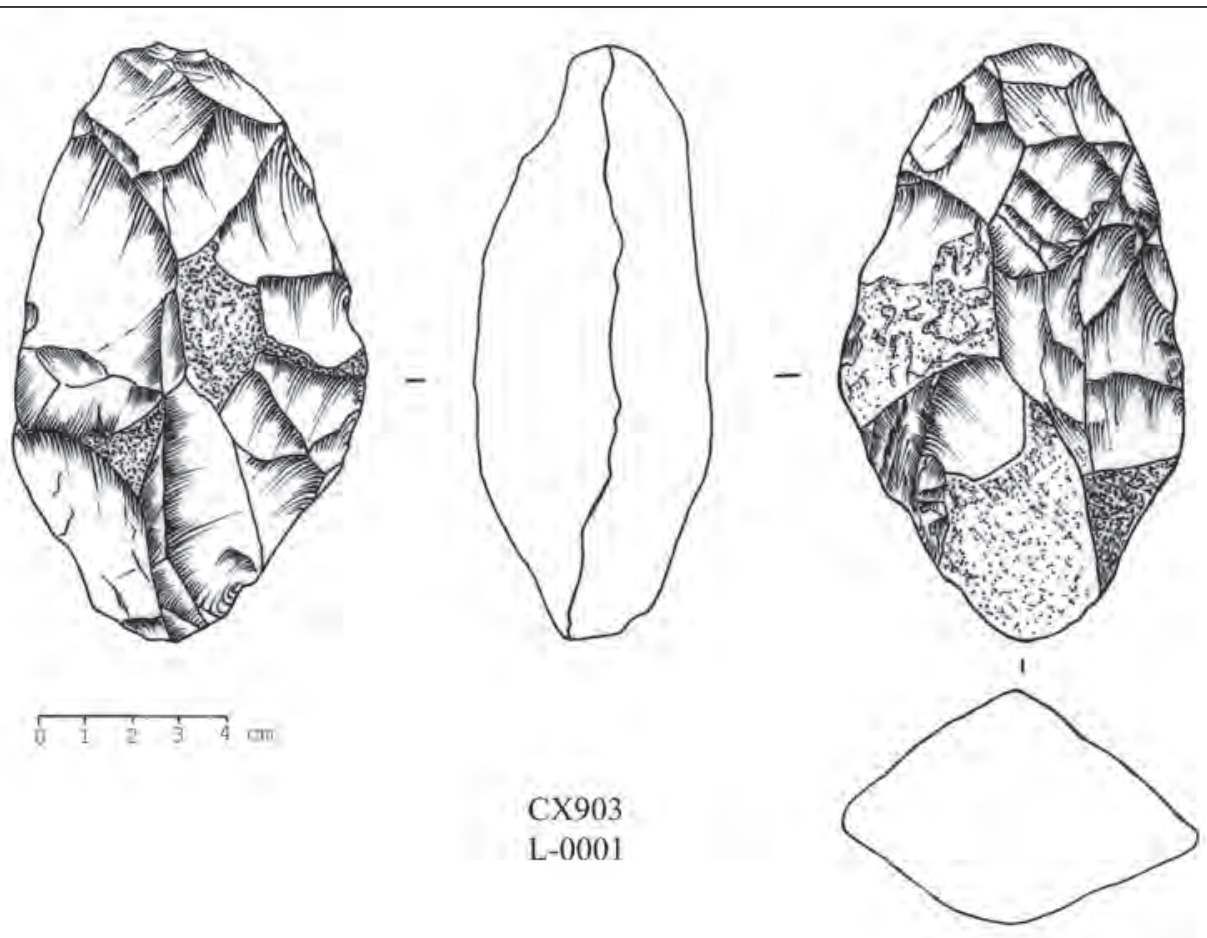

Figura 7. Preforma de bifaz.

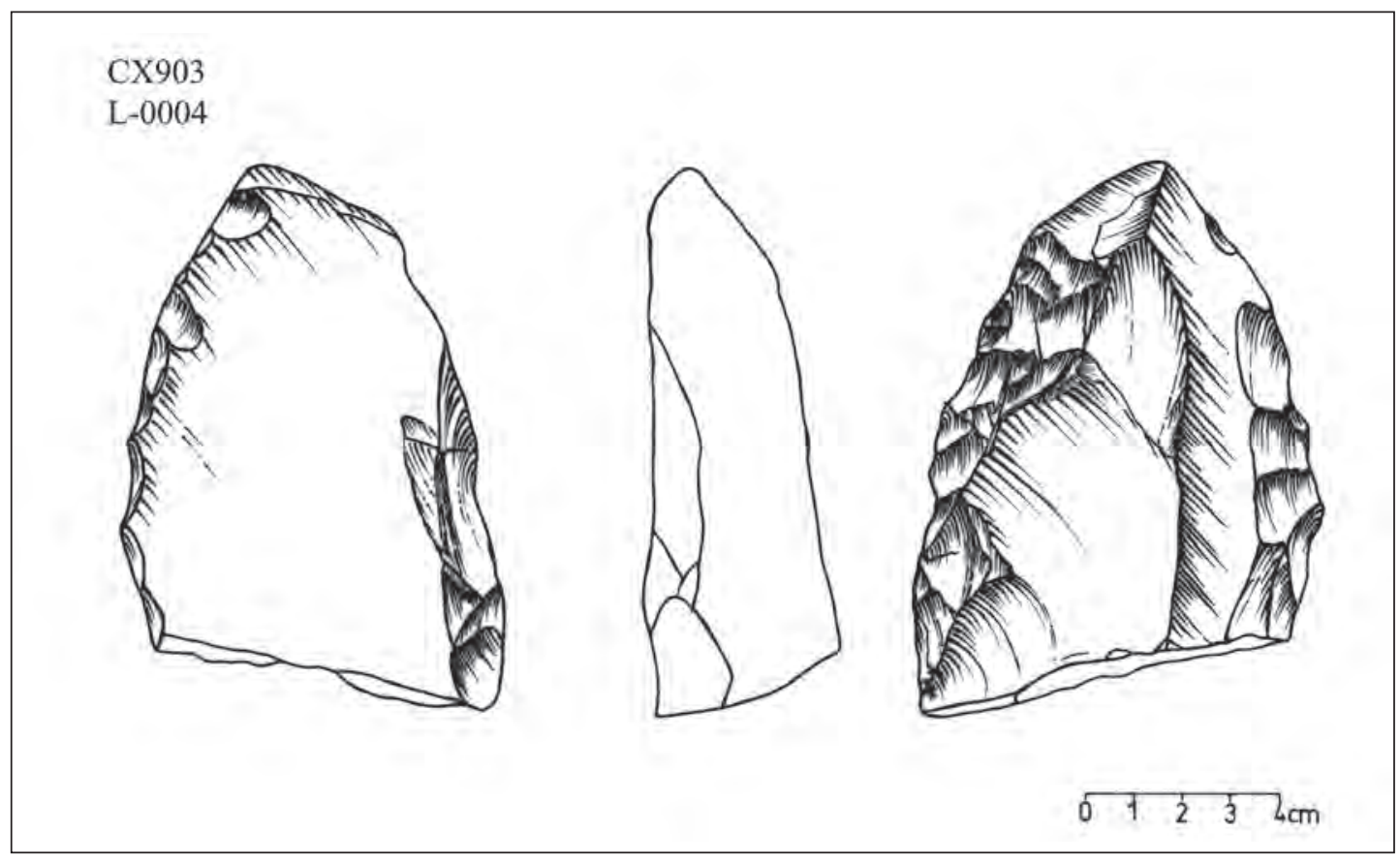

Figura 8. Preforma de bifaz sobre lasca. 


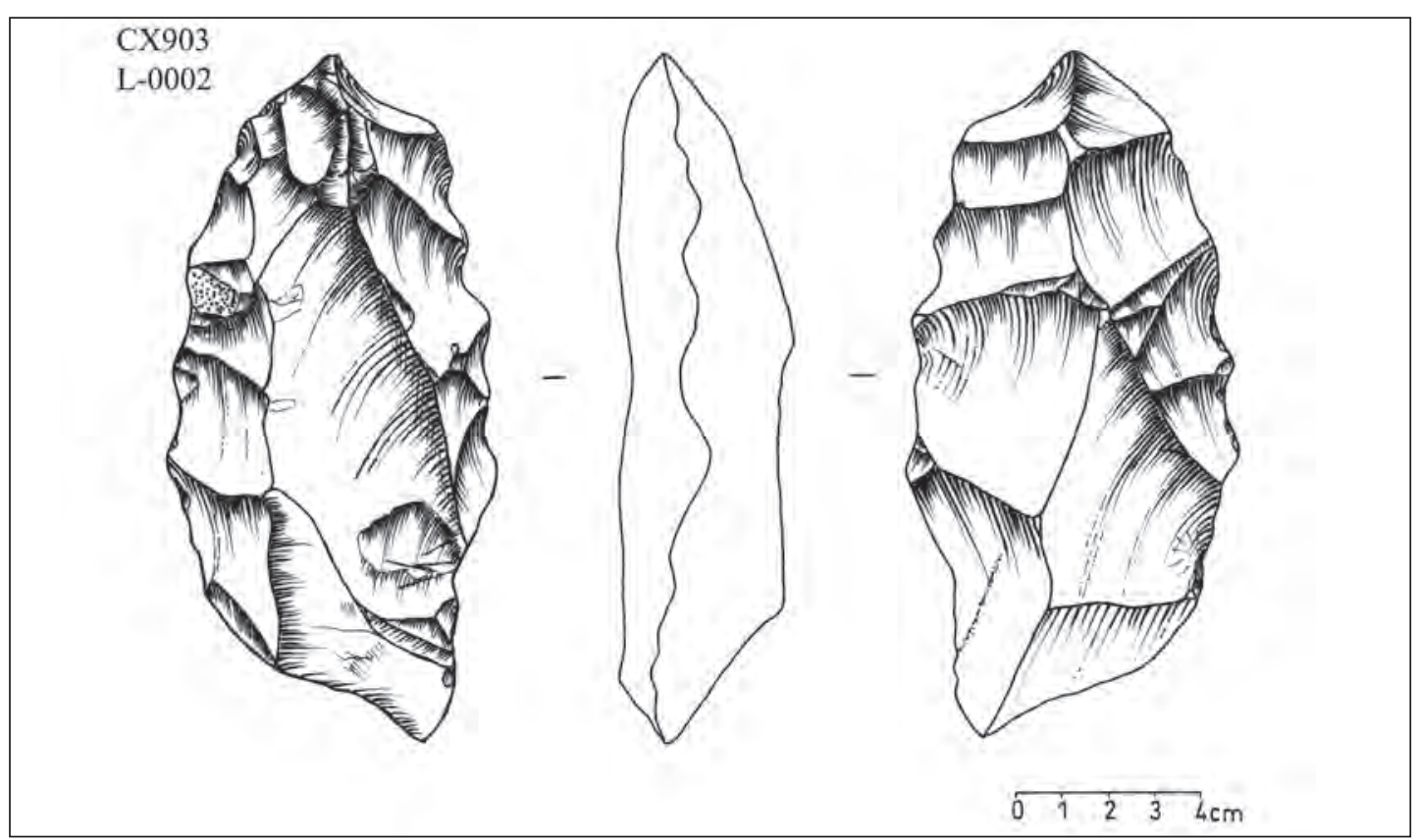

Figura 9. Preforma de bifaz.

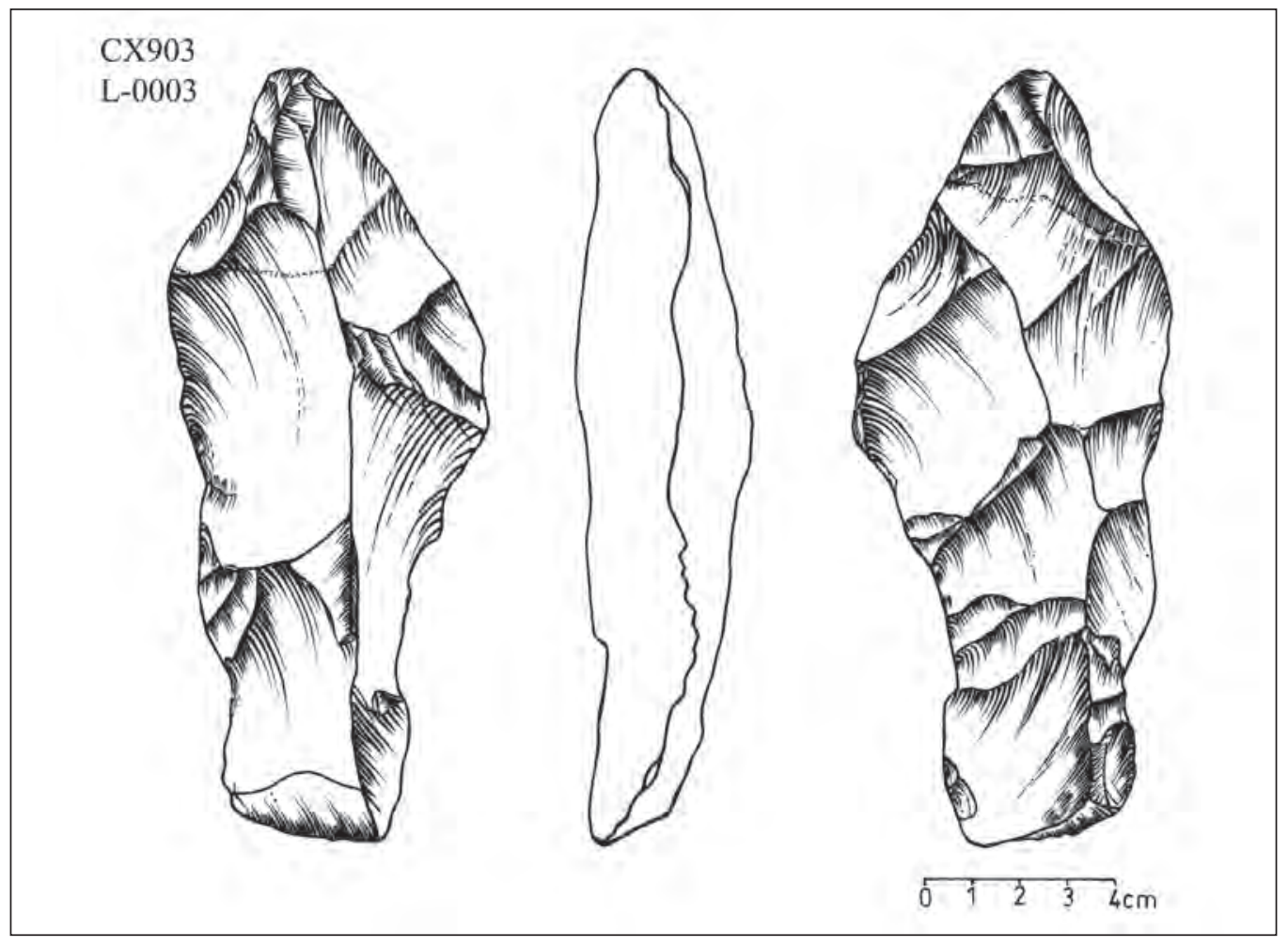

Figura 10. Preforma de bifaz. 
peso es de 184,31 gr. y el ángulo de borde bifacial es de $70^{\circ}$. Su forma es triangular irregular, en vista lateral se observan bordes paralelos irregulares y en sección trapezoidal. La percusión dura ha sido la predilecta durante su manufactura.

\section{Cadena Operativa}

El uso de la arenisca cuarzosa empaquetada de coloración marrón claro, fractura concoidal, pátina brillosa la hace exclusiva para la talla bifacial. Sin embargo, el contenido de diaclasas de cuarzo vuelve a este tipo de piezas inestables durante la talla. En muy posible que el blank elegido para confeccionar los bifaces sean piezas relativamente grandes cuyas formas son triedros y tetraédricas y en algunos casos se hace empleo de lascas de grandes dimensiones. La presencia de córtex en dos de las piezas puede sustentar nuestras hipótesis, asimismo la pieza L-0001 la de gran dimensión y peso puede permitir aproximarnos a reconstruir el blank elegido de al menos dimensiones de $150 \mathrm{x} 100 \mathrm{~mm}$. No se tiene desechos de talla para poder establecer fases concretas de la manufactura de las piezas. Sin embargo, al menos las preformas indican fase de decorticado, talla alterna y su puesta en forma.

\section{El Yacimiento CX943}

\subsection{UBICACIÓN}

Cerro Santa Ana, península de Paraguaná.

\subsection{TIPOLOGÍA}

\begin{tabular}{|c|c|c|c|c|}
\hline \multicolumn{5}{|c|}{ Tecno tipología lítica del sitio CX943 } \\
\hline Grupo & Tipo & № & $\%$ \\
\hline Bifacial & A.1 & Preforma de bifaz & 1 & $100 \%$ \\
\hline \multicolumn{2}{|c|}{ Total de piezas líticas antrópicas } & 1 & $100 \%$ \\
\hline
\end{tabular}

\subsection{OBSERVACIÓN A LOS MATERIALES LÍTICOS Y TIPOLOGÍA}

Una única preforma de bifaz proviene de este sitio. El lítico L-0006, es una pieza incompleta, definida tipológicamente en el grupo A.1, está modificada sobre una arenisca cuarzosa de pátina brillosa, color gris claro y de buena calidad para la talla. Tiene una longitud de $119 \mathrm{~mm}$, ancho de 75 $\mathrm{mm}$, espesor de $54 \mathrm{~mm}$ y un peso de 338 gr. La presencia de córtex en un $45 \%$ en una de sus facetas, delata el origen del blank de muy posible forma tetraédrica. El máximo ancho se localiza en la parte mesial y su máximo espesor en el tercio inferior de la pieza. El ángulo de borde bifacial mide entre $70^{\circ}$ a $80^{\circ}$. La forma de sus vistas frontal y lateral es triangular irregular y su sección romboidal irregular. Su proceso de reducción por percusión dura es evidente y presenta una fractura transversal por tecnología.

\section{Cadena Operativa}

Se dificulta la posibilidad de proponer la cadena operatoria del sitio, debido a que contamos tan solo con la presencia de una preforma de pieza bifacial. La cuarcita areniscosa guarda uniformidad con la materia prima de otros yacimientos aquí descritos.

\section{El Yacimiento CX945}

\subsection{UBICACIÓN}

Cerro Santa Ana, península de Paraguaná. 


\subsection{TIPOLOGÍA}

\begin{tabular}{|c|c|c|c|c|}
\hline \multicolumn{5}{|c|}{ Tecno tipología lítica del sitio CX945 } \\
\hline \multicolumn{2}{|l|}{ Grupo } & Tipo & № & $\%$ \\
\hline \multirow{2}{*}{ Bifacial } & A.2 & Fragmento mesial de punta bifacial & 2 & $33,3 \%$ \\
\hline & A.3 & Fragmento meso apical de punta bifacial & 3 & $50 \%$ \\
\hline Útiles a posteriori & B2.1 & Lasca modificada a posteriori & 1 & $16,7 \%$ \\
\hline \multicolumn{3}{|c|}{ Total de piezas antrópicas } & 6 & $100 \%$ \\
\hline
\end{tabular}

\subsection{OBSERVACIÓN A LOS MATERIALES LÍTICOS Y TIPOLOGÍA}

El grupo A.2 está conformado por la presencia de dos fragmentos mesiales de punta bifacial. La pieza L-0008, se observa bien configurada estando en una fase final de talla (Fig. 11). Sus medidas son de $62 \mathrm{x}$ $45 \times 13 \mathrm{~mm}$ y peso de $37,73 \mathrm{gr}$. El ángulo de borde bifacial varía entre $75^{\circ}$ a $80^{\circ}$. La silueta es triangular, su forma latera es paralelo recto y sección recto convexo. Los negativos y nervaduras profundas se asocia a la utilización de percutor duro y eventualmente percusión blanda. Se observan dos fracturas transversales, una ubicada en a parte apical de la pieza y en su parte mesial, son típicas por tecnología. Sobre sus bordes se observan una serie de retoques tenues, efectuados durante la finalización de la talla. Estos se delinean de manera recta, extensión corta, inclinación abrupta, localizándose en los bordes laterales izquierdo y derecho, su morfología es paralela irregular, posición bifacial y distribución continua.

La pieza L-0011 (Fig. 12) presenta dos fracturas en típica lengüeta debido a causas tecnológicas. A juzgar por su peso de 13,03 gr, eje de equilibrio y forma, se trata de una punta finalizada. Sus medidas son de 50 x 22 × $10 \mathrm{~mm}$. El ángulo de borde bifacial oscila entre $55^{\circ}$ y $60^{\circ}$, siendo esta de inclinación semiabrupta. La tecnología empleada muy posible ha sido la percusión con percutor blando. Su silueta es triangular, su vista de perfil indican bordes paralelos rectos convergentes y sección biconvexa sin irregularidades en su simetría. Sus bordes laterales ligeramente muestran cierta sinuosidad en zigzag lo cual prueba que se ha reducido la pieza de forma alterna ejerciendo presión en los bordes. La delineación de los retoques son convexos y de extensión corta, disponiéndose sobre la pieza de forma paralela irregular y distribución continua.

El grupo tipológico A.3 está determinado por la presencia de tres fragmentos meso apicales de puntas bifaciales. Las medidas de la pieza L-0009 son de 73 x 27 x $9 \mathrm{~mm}$. Tiene un peso de 19,07 gr. El máximo ancho y espesor se localizan en la parte mesial de la punta. Se trata de una pieza finalizada pues el eje de equilibrio es simétrico. El ángulo de borde bifacial fluctúa entre $55^{\circ}$ a $60^{\circ}$. Su silueta es triangular, perfil paralelo recto convergente, sección biconvexa. La tecnología empleada ha sido muy posible la percusión blanda. La delineación de los retoques es convexa, extensión corta, localizándose en toda la periferia de la pieza, la forma de los retoques sobre la pieza se disponen de manera paralela irregular y continua en ambas facetas y bordes de la pieza. La fractura en lengüeta en la parte mesial indican su origen por causas tecnológicas.

La pieza L-0010, fracturada también por causas tecnológicas tiene medidas de 67 x 26 x $12 \mathrm{~mm}$, su peso es de 22,32 gr. El ángulo de borde bifacial oscila entre $55^{\circ}$ y $60^{\circ}$. Su simetría aún no es perfecta, siendo su silueta triangular ligeramente irregular, su vista lateral es paralela convergente y su sección biconvexa. Sobre ésta es muy probable el empleo de percusión dura.

El fragmento de punta bifacial L-0012 (fig. 13), presenta medidas de 77 x 29 x 12 mm y un peso de 27,09 gr. Su ángulo de borde activo oscila entre $60^{\circ}$ a $70^{\circ}$. La silueta de esta pieza es triangular, la forma de su vista lateral es paralelo convergente y sección biconvexa. La percusión dura es muy probable debido aún a la reducción alterna determinada en sus bordes laterales. La delineación de los retoques 


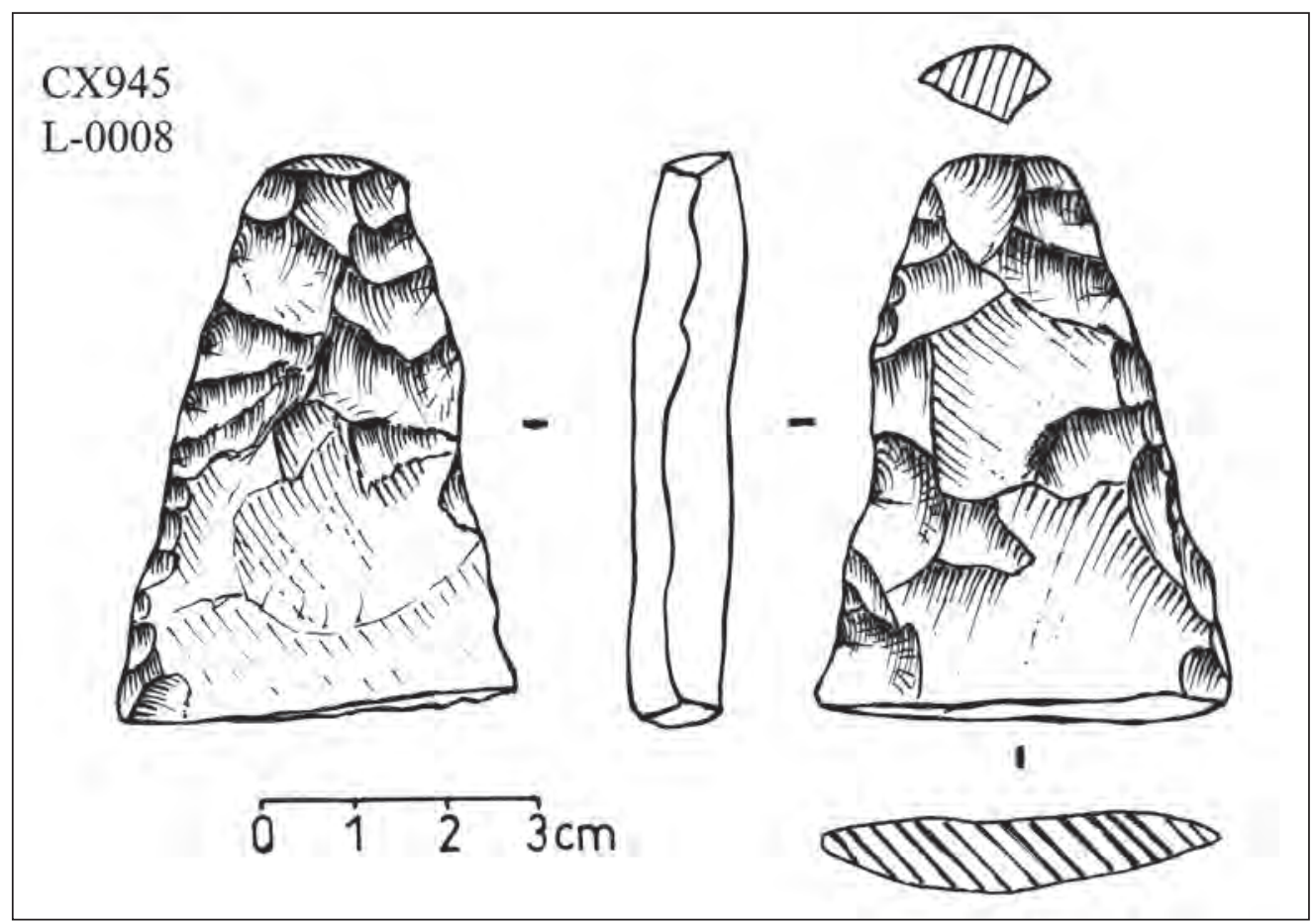

Figura 11. Fragmento mesial de punta bifacial.

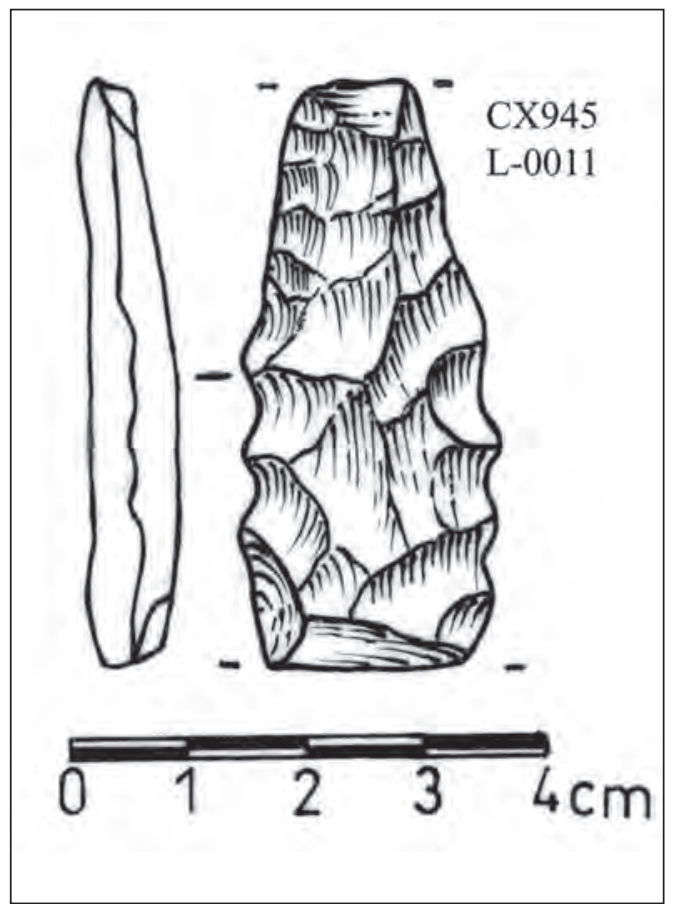

Figura 12. Fragmento mesial de punta bifacial.

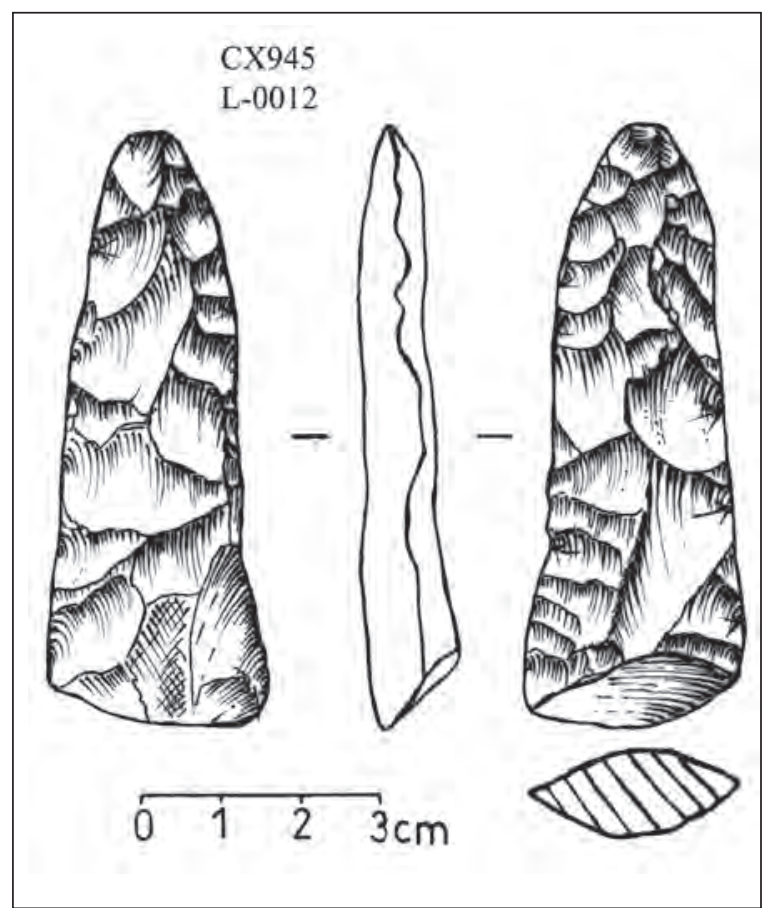

Figura 13. Fragmento meso apical de punta bifacial. 


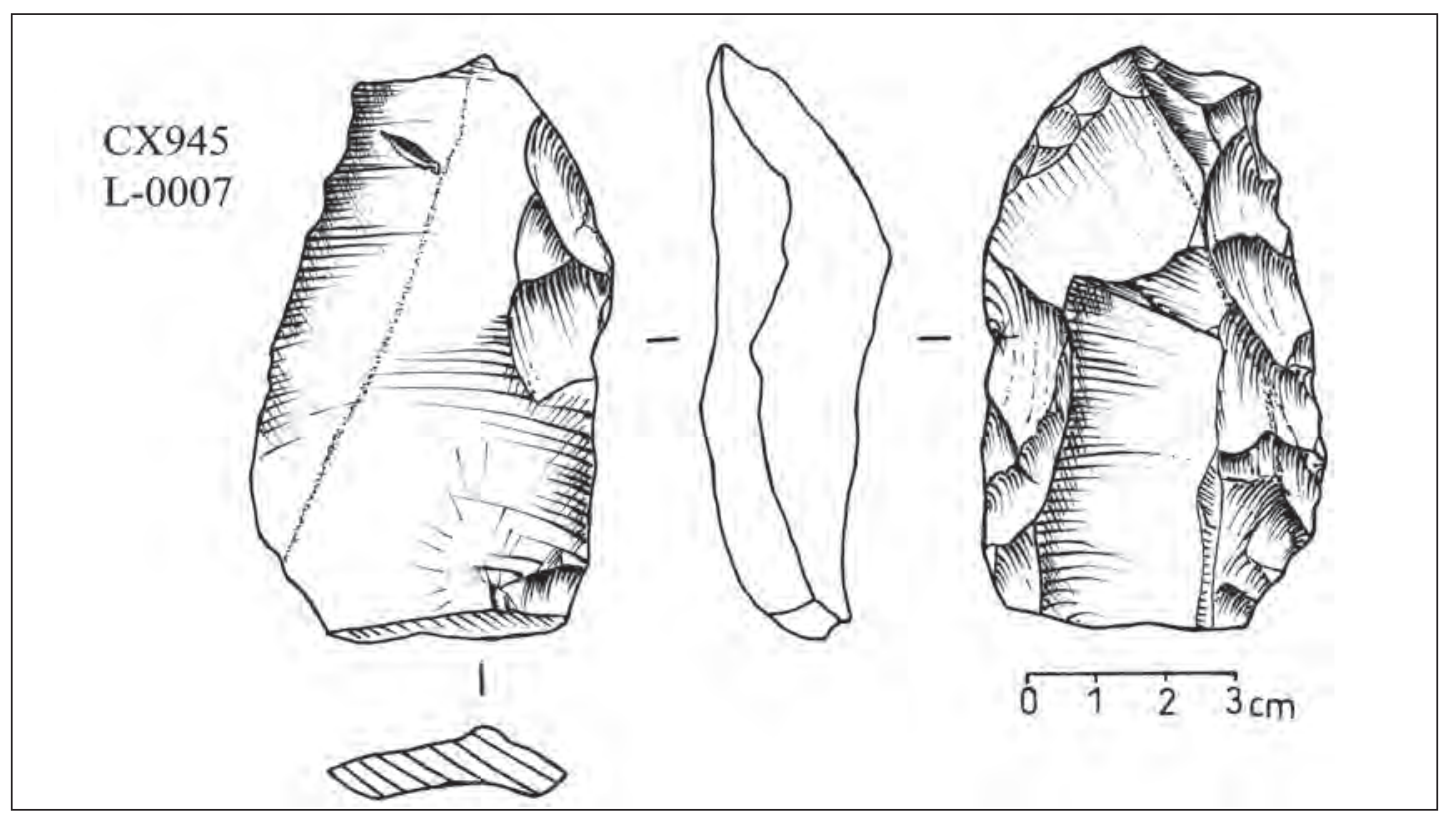

Figura 14. Lasca modificada a posteriori.

es recta irregular, extendiéndose de manera corta, se localiza en toda la periferia de la pieza, su morfología es paralela irregular y de posición bifacial. Esta pieza esta en fase final de reducción debido a pequeñas irregularidades en su eje de equilibrio.

Una lasca modificada a posteriori L-0007 pertenece al grupo B2.1. Sus medidas son de $82 \mathrm{~mm}$ ancho $55 \mathrm{~mm}$ y espesor de $27 \mathrm{~mm}$ (Fig. 14). Su peso es de 126,14 gr. el ancho y espesor del talón miden 36 x $11 \mathrm{~mm}$. El ángulo de expulsión es de $65^{\circ}$, el ángulo de borde activo distal es de $80^{\circ} \mathrm{y}$ el borde activo del borde derecho mide $75^{\circ}$. Su silueta es rectangular, lateral rectangular irregular y sección de forma trapezoidal. El talón es liso y bulbo prominente el cual respalda su obtención por percutor de piedra. El borde distal es grueso, sin presencia de córtex y se observa sobre su dorsal el negativo de una lasca reflejada. La arenisca presenta imperfecciones cruzando de forma lateral vertical una diaclasa de cuarzo. La delineación del retoque es convexa de extensión corta sobre la dorsal, localizándose sobre el borde derecho y distal de la pieza, finalmente de morfología paralela irregular y continua.

\section{Cadena Operativa}

La cuarcita areniscosa empaquetada ha sido la predilecta para la talla. Sus colores varían desde un gris claro a un rojizo y marrón claro. La presencia de diaclasas al menos en las piezas L-0009 y L-0007 ponen en riesgo la talla final de las piezas. Se observa en este sitio la presencia de bifaces. No tenemos desechos de talla que nos indique que su modificación se efectúe in situ. Sin embargo, algunas piezas burdas y casi finales pueden indicar muy posible actividades de talla final (e.g. retoque y/o finalización) de piezas bifaciales en este yacimiento. Las fracturas en lengüeta son debidas a causas tecnológicas más que por las impurezas en la roca.

\section{Sobre La CALIBRACIÓN DE FECHADOS RADIOCARBÓNICOS EN LA ZONA DE CONVERGENCIA INTERTROPICA}

La edad radiocarbónica es comúnmente estimada y expresada en muchas publicaciones en años B.P. (years before the present), teniendo por costumbre el uso del año 1950 A.D. como 0 B.P. Debido a una 
serie de convenciones internacionales sabemos que el empleo convencional de las siglas B.P hacen referencia a los fechados con valores no calibrados, mientras que BC/AD sugieren valores radiocarbónicos calibrados en años calendáricos nuestros (Taylor, 1987: 4-6).

Durante el empleo del programa OxCal v.4.1 se ha preferido usar la curva de calibración InCal09 (Reimer et al. 2009: 1111-1150) utilizada para fechados del hemisferio norte debido a la edad temprana de las muestras y al alcance de la curva de calibración. Además, se dispuso la obtención de datos a dos sigmas para evaluar un margen amplio de tiempo durante la calibración.

Por otro lado, viendo que los fechados pueden estar alterados muy posible debida a la intensa radiación solar, como también muy posible al efecto Suess ya detectada en muestras marinas del Cariaco Basin procedentes de Islas Tortugas, Boca del Medio y Los Testigos (Ochsenius 1979: 18; Guilderson et al. 2005: 57-65), se suma además la proximidad de los sitios a la zona de convergencia intertropical (Intertropical Convergence Zone, ITCZ). Sobre este último, diversas publicaciones ya han tratado sobre la incertidumbre de las calibraciones de ${ }^{14} \mathrm{C}$ desde los sitios que se localizan en el neo-tropico y trópico, concluyendo que en el ITCZ debido a los cambios de estación se desplaza por efectos del viento $\mathrm{CO}_{2}$ desde el hemisferio norte y de igual forma en otra parte del año el viento desplaza $\mathrm{CO}_{2}$ desde el hemisferio sur, jugando este fenómeno un rol determinante en la alteración de los fechados radiocarbónicos en el Coriaco Basin (McCormac et al. 2004: 1188; Westbrook et al. 2004). Por estas razones, se ha priorizado la revisión de posibles efectos reservorio sobre muestras terrestre en el Cariaco Basin. Sin embargo, no existen estudios que precisen una compensación a estas alteraciones (Hughen et al. 1998: 489-490). Sabiendo estos datos realizaremos a continuación la calibración de los fechados del sitio arqueológico de Taima-Taima debido a las asociaciones de resto de animales pleistocénicos con material lítico Joboide y asociar su temporalidad a esta colección.

\section{TAIMA-TAIMA}

Sobre este sitio queremos simplemente abordar los fechados radiocarbónicos en conjunto, tomando para ello el trabajo de Bryan y Gruhn y someterlos a la calibración (Bryan \& Gruhn 1979: 55-56, tables 1 and 2). Los fechados de Taima-Taima proceden de diferentes perfiles ordenados por unidades y niveles estratigráficos y expresados en años radiocarbónicos BP deslindando en estos los fechados radiocarbónicos consistentes e inconsistentes (Bryan \& Gruhn 1979: 56). Nos limitaremos tan solo en corregir los fechados que han sido considerados como consistentes. Ocho fechados provienen del perfil A de Taima-Taima tomados durante las excavaciones de 1968 de la esquina noreste, sección 38 asociadas a una serie de capas de arcilla distinguidas según las características del suelo como Unidad I (grey sand) y Unidad III (black clay). Es en la unidad I donde se ha podido asociar los huesos de animales y posibles actividades de matanza (Tamers 1971: 34-35). Los fechados han sido clasificados por Bryan y Gruhn (1979: 55) de la siguiente manera:

Tabla 3. Fechados del Perfil A.

\begin{tabular}{|c|c|c|c|}
\hline \multicolumn{4}{|c|}{$\begin{array}{c}\text { Perfil A (esquina NE, sección } 38 . \\
\text { Unidad III, Black Clay) }\end{array}$} \\
\hline Cod. Lab. & Valor en BP. & Profundidad \\
\hline IVIC-657 & 9650 & 80 & $0,65-0,75 \mathrm{~cm}$ \\
\hline IVIC-658 & 9650 & 100 & $0,75-0,85 \mathrm{~m}$ \\
\hline IVIC-659 & 10140 & 90 & $0,85-0,95 \mathrm{~m}$ \\
\hline
\end{tabular}

\begin{tabular}{|c|c|c|c|}
\hline \multicolumn{4}{|c|}{ Perfil A, Grey Sand, Unidad I } \\
\hline Cod. Lab. & Valor en BP & Profundidad \\
\hline IVIC-660 & 12660 & 120 & $1,50-1,65 \mathrm{~m}$ \\
\hline IVIC-661 & 12660 & 120 & $1,65-1,80 \mathrm{~m}$ \\
\hline IVIC-662 & 13390 & 130 & $1,80-1,95 \mathrm{~m}$ \\
\hline IVIC-663 & 13130 & 130 & $1,95-2,10 \mathrm{~m}$ \\
\hline IVIC-664 & 12730 & 120 & $2,10-2,25 \mathrm{~m}$ \\
\hline
\end{tabular}


Asimismo, ocho fechados más fueron obtenidos de la esquina SE del perfil B, sección 38, al igual que en el perfil A han sido ordenados de manera secuencial teniendo en cuenta las profundidades de donde fueron tomadas. Estas han permitido realizar comparaciones con el perfil A. En este caso los fechados del perfil B clasificados por Bryan y Gruhn (1979: 55) son las siguientes:

Tabla 4. Fechados del Perfil B.

\begin{tabular}{|c|c|c|c|c|c|c|c|}
\hline \multicolumn{8}{|c|}{ Perfil B (esquina SE, sección 38) } \\
\hline Cod. Lab. & \multicolumn{2}{|c|}{ Valor en BP } & \multirow{2}{*}{$\begin{array}{c}\text { Profundidad } \\
0,65-0,75 \mathrm{~cm}\end{array}$} & \multirow{2}{*}{$\frac{\text { Cod. Lab. }}{\text { IVIC-669 }}$} & \multicolumn{2}{|c|}{ Valor en BP } & \multirow{2}{*}{$\begin{array}{c}\text { Profundidad } \\
1,65-1,80 \mathrm{~m}\end{array}$} \\
\hline IVIC-665 & 9860 & 110 & & & 12770 & 120 & \\
\hline IVIC-666 & 10030 & 90 & $0,75-0,85 \mathrm{~m}$ & IVIC-670 & 12990 & 260 & $1,80-1,95 \mathrm{~m}$ \\
\hline IVIC-667 & 10290 & 90 & $0,85-0,95 \mathrm{~m}$ & IVIC-671 & 13180 & 130 & $1,95-2,10 \mathrm{~m}$ \\
\hline IVIC-668 & 13390 & 130 & $1,50-1,65 \mathrm{~m}$ & IVIC-672 & 14010 & 140 & $2,10-2,25 \mathrm{~m}$ \\
\hline
\end{tabular}

Finalmente los autores realizan un estudio detallado de los fechados y sus contextos finalizando, con una tabla resumen en dónde se exponen los resultados de laboratorio más consistentes e inconsistentes procedentes de Taima-Taima, la tabla vertida es la que se muestra en la siguiente página.

Al someter los resultados de laboratorio considerados como consistentes al programa de calibración Oxcal 4.1, se ha obtenido una superposición lógica de las mismas. Estos tienen un rango que oscila aproximadamente desde los 8000 a $16000 \mathrm{cal} \mathrm{BC}$., estos se exponen en la tabla 6.

En la unidad III, la muestra (IVIC-657), ha arrojado un fechado calibrado que oscila entre 92378804 calBC. Si bien este guarda una relación secuencial el fechado se muestra alterado debido a que este cae sobre un "plateux". La muestra (IVIC-658) es un caso similar al anterior, pues se muestra alterada, resultando la calibración en un rango que oscila entre 9245 calBC-8745 calBC. La muestra (IVIC-665), ha arrojado un alcance temporal de 9266-8753 calBC. Luego, las muestras (IVIC-666) (IVIC659) e (IVIC-667), presentan los años calendáricos en orden consecutivos de 9766-9306 calBC, 100419398 calBC y 10430-9768 calBC, todos con evidencias de alteraciones debido a que recaen nuevamente sobre "plateux" (cf. tabla 6).

La unidad I está conformada por catorce muestras de laboratorio los cuales también han mostrado un resultado secuencial lógico. Esta unidad tiene un margen temporal que fluctúa desde los 11464 a 14850 calBC. Un 95\% de las muestras calibradas se presentan alteradas nuevamente por la presencia de "plateux", empero al menos las muestras IVIC-662 y IVIC-668, presentan solo ligeras alteraciones en comparación a otras (cf. Tabla 7, fechados sombreados en gris).

Creemos que la investigación y las asociaciones de piezas tipo Joboide con huesos de animales pleistocénicos realizada en Taima-Taima resultan creíbles, siendo este uno de los sitios más consistentes. Si bien los fechados radiocarbónicos exhiben en gran mayoría alteraciones, una coherente secuencia temporal se asocia con el orden estratigráfico de las excavaciones efectuadas lo cual da credibilidad a la asociación temporal Pre-Clovis en Taima-Taima. No olvidemos que las alteraciones pueden ser debidas a posibles efectos reservorios que afecten a las muestras terrestres y y estas alteraciones no han sido investigados a profundidad. Asimismo, el desplazamiento de $\mathrm{CO}_{2}$ y los fenómenos climatológicos en el Cariaco (e.g. insolación, cambio estacional y desplazamiento del viento), pueden jugar un rol fundamental para el entendimiento de tales alteraciones durante fines del Pleistoceno e inicios del Holoceno en la península de Paraguaná.

\section{Discusión Y CONCLUSIÓN}

Se ha preferido utilizar de manera cautelosa el término Joboide debido a las semejanzas con el clásico material lítico definido por José María Cruxent referente al sitio clásico El Jobo procedente de Pedregal. 
Tabla 5. Fechados radiocarbónicos consistentes e inconsistentes de Taima-Taima. Tomado de Bryan y Gruhn (1979: 56, table: 2).

\begin{tabular}{|c|c|c|c|c|c|c|}
\hline $\begin{array}{c}\text { Unidad estratigráfica y material } \\
\text { datado }\end{array}$ & \multicolumn{3}{|c|}{ Datos consistentes } & \multicolumn{3}{|c|}{ Datos inconsistentes } \\
\hline \multirow{7}{*}{$\begin{array}{l}\text { Black Clay (Unit. III): organic carbon } \\
\text { content of "soil" }\end{array}$} & \multicolumn{2}{|c|}{ Valor en BP. } & \multirow{2}{*}{$\begin{array}{l}\text { Cod. Lab } \\
\text { IVIC-657 }\end{array}$} & \multicolumn{2}{|c|}{ Valor en BP. } & \multirow{2}{*}{$\begin{array}{c}\text { Cod. Lab } \\
-\end{array}$} \\
\hline & 9650 & 80 & & - & - & \\
\hline & 9650 & 110 & IVIC-658 & - & - & - \\
\hline & 9680 & 110 & IVIC-665 & - & - & - \\
\hline & 10030 & 90 & IVIC-666 & - & - & - \\
\hline & 10140 & 90 & IVIC-659 & - & - & - \\
\hline & 10290 & 90 & IVIC-667 & - & - & - \\
\hline \multirow{14}{*}{$\begin{array}{l}\text { Convoluted Grey Sand (Unit. I): root } \\
\text { probably extending from surface of } \\
\text { Unit I. All IVIC dates on organic carbon } \\
\text { content of "soil", except IVIC 191-1 on } \\
\text { organic carbon content of bone. Others } \\
\text { dates on wood associated with mast- } \\
\text { odon skeleton excavated in } 1976\end{array}$} & 11860 & 130 & IVIC-655 & - & - & - \\
\hline & 12580 & 150 & IVIC-627 & - & - & - \\
\hline & 12620 & 120 & IVIC-661 & - & - & - \\
\hline & 12660 & 120 & IVIC-660 & - & - & - \\
\hline & 12730 & 120 & IVIC-664 & - & - & - \\
\hline & 12770 & 120 & IVIC-669 & - & - & - \\
\hline & 12980 & 85 & SI-3316 & - & - & - \\
\hline & 12990 & 260 & IVIC-670 & - & - & - \\
\hline & 13000 & 200 & Birm-802 & - & - & - \\
\hline & 13010 & 280 & IVIC-191-1 & - & - & - \\
\hline & 13130 & 130 & IVIC-663 & 13880 & 120 & USGS-247 \\
\hline & 13180 & 130 & IVIC-671 & 14010 & 140 & IVIC-672 \\
\hline & 13390 & 130 & IVIC-662 & 14200 & 300 & UCLA-2133 \\
\hline & 13390 & 130 & IVIC-668 & - & - & - \\
\hline $\begin{array}{c}\text { Bone probably from Cooble Pavement } \\
\text { (organic carbon) }\end{array}$ & 14440 & 435 & IVIC-191-2 & 7590 & 100 & IVIC-191-B \\
\hline
\end{tabular}

El análisis efectuado nos ha permitido confirmar la presencia de preformas, esbozos, puntas bifaciales y unifacial en la península de Paraguaná. La materia prima de arenisca cuarzosa ha permitido identificar segmentos de la cadena operativa lítica. Selección de grandes piezas con formas muy posible triédricas, tetraédricas y posibles guijas para confeccionar piezas bifaciales a percusión dura han sido la predilecta. La relación morfotecnológica de esta colección Joboide de Paraguaná frente a líticos de El Jobo de Pedregal ha podido ser establecido preliminarmente. Estas comparaciones son generales y se han establecido a partir de algunas fotografías y descripciones publicadas, las cuales guardan semejanzas por sus formas y dimensiones con la punta unifacial del sitio CX658 y las preformas de bifaces identificadas en la colección analizada. El empleo de lascas alargadas reducida 
Tabla 6. Fechados radiocarbónicos de Taima-Taima calibrados a dos sigmas, resultando en orden secuencial y corroborando la propuesta por Bryan and Gruhn (1979: 53-58).

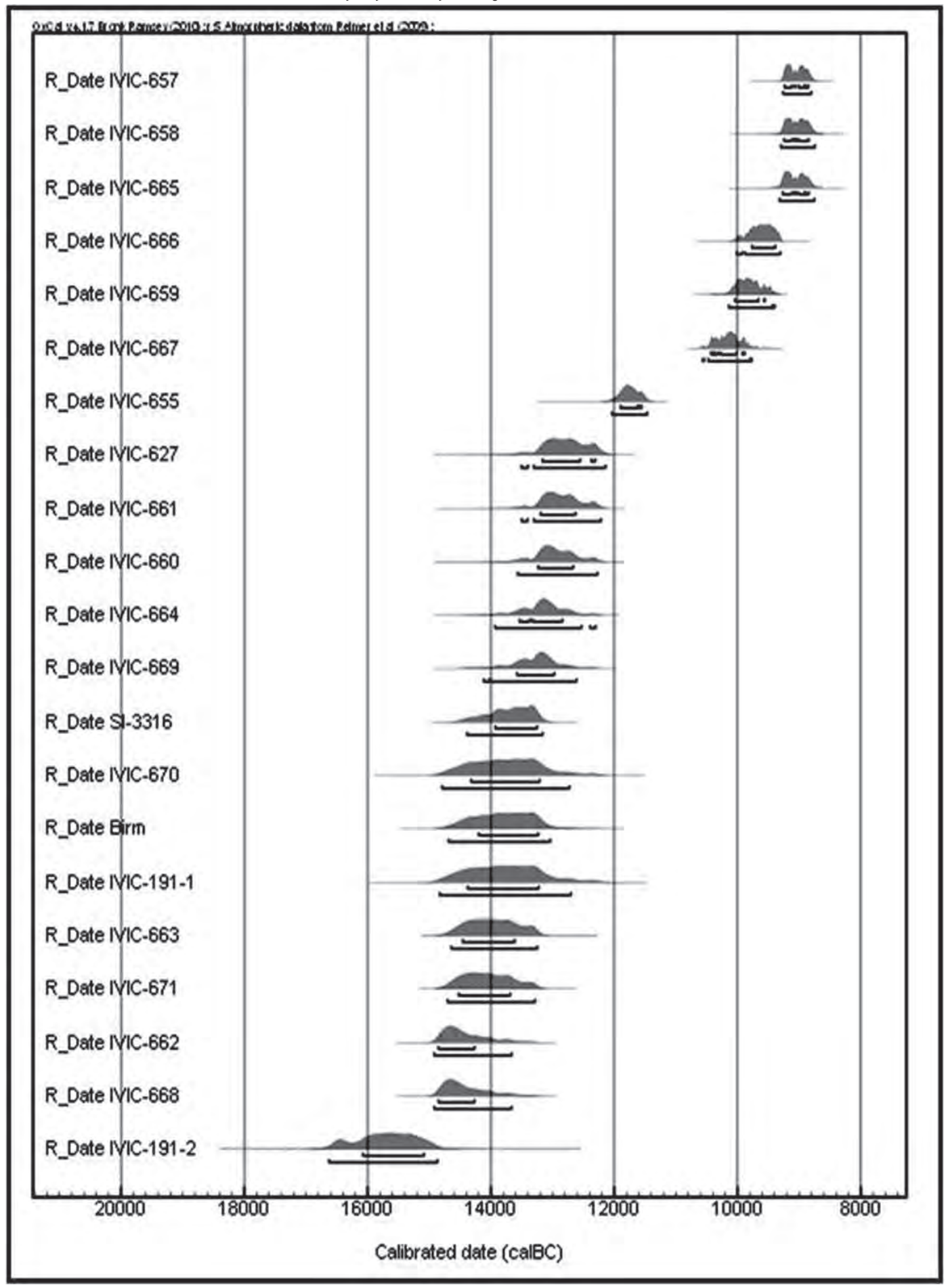


unifacial y bifacialmente pone en evidencia el tipo de soporte requerido para confeccionar toda una gama de artefactos (e.g. Cruxent \& Rouse, 1956: 174-175, fig. 2-3; Cruxent,s/f: 9-14, fig. II-VII; Cruxent \& Rouse, 1961: 39; fig. 37, plancha 20). Igualmente la materia prima determinada en nuestros estudios guarda concordancia con la materia prima registrados en El Pedregal y la península de Paraguaná (cf. Szabadics, 1997: 65-66, 71, fotos № 24-25, 71).

Por otro lado, resulta evidente que el trabajo de Cruxent y de Szabadics es seminal en la península de Paraguaná y es necesario mayores investigaciones en la zona que explique la presencia de puntas Clovis, Folsom y Joboide en esta área (Szabadics 1997: 104, 105, 114). El termino tipológico "hachas de piedra" (Rouse \& Cruxent 1963c: 30, 1963d: 37; Szabadics, 1997: 65-67; 80-83; Cruxent, 1967: 3) y "lascas levallois" (Cruxen, 1983: 249-256) empleada sobre los materiales líticos de El Jobo debe de ser desechada, debido a que no existe ninguna relación tecnológica con la industria lítica europea y más bien estamos frente a preformas de bifaces, relacionadas al primer estadio de talla.

Los fechados radiocarbónicos y su calibración han sido satisfactorios. Las alteraciones de los fechados al momento de la calibración pueden deberse a múltiples factores, pudiendo deberse a la toma de la muestra, hasta el desplazamiento de $\mathrm{CO}_{2}$ por el viento en diferentes estaciones del año procedentes desde el hemisferio sur y norte hacia la zona de convergencia intertropical en el Cariaco. Los estudios de estas alteraciones de $\mathrm{CO}_{2}$ sobre el material terrestre merecen un estudio detallado para poder determinar las compensaciones que se deben de tener en cuenta al momento de la calibración radiocarbónica a años calendáricos nuestros. Estudios de estas alteraciones denominadas como efecto reservorio ya se efectúan en el Cariaco pero aplicadas exclusivamente para muestras marinas.

Las referencias geológicas también ha revelado que Cerro Santa Ana es tema de debate científico y existen dos posturas teóricas sobre su origen. En primer lugar se argumenta que se trataría de un volcán alóctono debido a la presencia de cristales contenidos en las rocas de basalto, mientras que otros argumentan que estaríamos frente a una masa magmática que no llegó a erupcionar y se enfrió lentamente. Al margen de estas explicaciones, el análisis geológico sobre los líticos ha determinado que la materia prima empleada en la colección en estudio ha sido la arenisca cuarzosa, el cual coincide con la formación ígnea metamórfica del cerro Santa Ana. Este dato guarda relación con la materia prima documentada al sur oeste y de la base del cerro Santa Ana cuyos sitios están catalogados con los rótulos CX405, CX433, CX658, CX903, CX943 y CX945. A partir de la determinación de la materia prima podemos argüir hipotéticamente lo siguiente: Que los primeros habitantes de la península de Paraguaná se asentaron cercanamente a la cantera de arenisca cuarzosa para aprovisionarse de ella. Si esto se compara con la serie clásica de El Jobo localizado en El Pedregal, la recurrencia de este tipo de materia prima para confeccionar preformas y puntas bifaciales es la misma. Muy posible el desplazamiento de este grupo humano desde la península de Paraguaná hasta El Pedregal o de manera inversa puede ser evidencia del recorrido de este grupo humano con la misma tecnología.

Creemos que los materiales aquí analizados pueden ser asociados temporalmente con los materiales liticos de tipo Joboide hallados en Taima-Taima. Debido a que Taima-Taima ha sido determinado como uno de los sitios representativos que presenta una cronología fiable hemos decidido realizar la calibración de los fechados radiocarbónicos. Los veinte y un fechados determinados como valederos han permitido obtener una sucesión de eventos que guardan relación con la estratigrafía registrada en este sitio. Las muestras (IVIC-662) e (IVIC-668) muestran ligeras alteraciones durante la calibración lo cual permite argumentar una ocupación y actividad Pre-Clovis con evidencias de líticos del tipo Joboide en asociación a restos de fauna Pleistocénica. Sobre este punto es necesario recordar que el paradigma Clovis viene siendo hoy reevaluado, debido al descubrimiento de artefactos líticos entre mil a ochocientos años más tempranos que la clásica ocupación Clovis. Un caso con evidencia de caza y huesos con huellas de corte se evidencia en el sitio Manis, donde se ha puesto en evidencia la incrustación de una punta de proyectil entre la vértebra y la costilla de un mastodonte y cuyos fechados radiocarbónicos llega entre 13860 a 13763 BP (Waters et al. 2011: 351-353). Por otro lado, 
investigaciones efectuadas en una serie de cuevas sumergidas en la península de Yucatan se han hallado restos humanos que datan entre 13610 a 13430 calBC, asimismo se ha reportado la presencia de restos de fauna pleistocenica sin confirmar su asociación con los restos óseos humanos encontrados (González et al. 2008: 1-24). Otro sitio reportado con artefactos pre-Clovis se localiza en el sitio Gault, en Texas (Collins et al. 2008:70-72). Estas evidencias pre-Clovis, resultan ser de especial importancia para poder evaluar la edad de la llegada y rutas de migración de los primeros americanos (Bryan 1986: 1-14). Otro sitio de edad muy temprana que contiene evidencias de los restos óseos de al menos seis mastodontes, registrándose en áreas de matanza y descarnado ha sido reportado en el sitio de Monte Verde en Chile (Dillehay 2000: 158), semejantes contextos se han reportado en Tibitó, en la Cueva del Medio, cueva de Mylodont, las Buitreras y Palli Aike.

No somos capaces aún de poder determinar con seguridad si las puntas del tipo El Jobo son exclusivamente un invento sudamericano. Si bien la cronología de Taima-Taima resulta ser pre-Clovis, no necesariamente sería un indicador real para poder argüir una invención propia sudamericana. Con esto no nos mostramos contrarios a las ideas de Bryan (1973: 245-254; 1975: 151-159), sino que aún requerimos de mayores registros morfotecnológicos de toda la industria de El Jobo para poder determinar y correlacionar con mayor precisión filiaciones y diferencias entre la industria lítica norteamericana versus la sudamericana.

En conclusión, mayores estudios no solamente sobre tipología, sino también temas que aborden las alteraciones de las muestras radiocarbónicas por efectos del clima, geología, estudios de los tipos de rocas seleccionadas para la confección de utensilios, variaciones del mar en tiempos pleistocénicos y la tecnología lítica son de suma urgencia en ésta área para el entendimiento del desplazamiento humano de los primeros pobladores venezolanos. Al menos nuestros estudios han determinado la selección de arenisca cuarzosa de muy posible grandes blanks de formas angulosas o guijas, mediante los cuales se detecta solo el primer estadio de decorticado y obtención de preformas bifaciales, seguido de un último estadio conformado por talla final con la obtención de puntas bifaciales y unifaciales. Asimismo, recalcamos que la tecnología del tipo Joboide documentada en el cerro Santa Ana de la península de Paraguaná, guarda estrecha semejanzas con las descripciones tecnológicas y morfología del complejo clásico El Jobo, localizado en el Pedregal a $90 \mathrm{~km}$ tierra adentro. Por lo tanto, creemos que mediante la identificación de la misma tecnología y selección de la materia prima es posible argumentar una ocupación y desplazamiento de un mismo grupo humano desde el cerro Santa Ana hasta el Pedregal. Siempre bajo este argumento resulta evidente que recorrer grandes distancias para los talladores Joboides no resulta difícil. Finalmente, las asociaciones temporales de los liticos del tipo Joboide asociadas con las muestras más tempranas procedentes de Taima-Taima IVIC-662 y IVIC-668, pueden ser asociadas con las piezas estudiadas en la presente investigación, por lo tanto, estas se remontan a edades que fluctúan entre 13664 y 14850 calBC, siendo las más tempranas de Venezuela y de clara edad pre-Clovis. 


\section{BiBLIOGRAFÍA}

BORDES, François

1981 Typologie du paleolitique ancien et Moyen. Bourdeux. Delmas. Publications de I'nstitut de préhistoire de l'université de Bourdeux. Centre National de la Recherche Scientifique.

BRYAN, Alan

1973 "Paleoenvironments and cultural diversity in late Pleistocene south America". En: Quaternary Research, 3 (2): 237-256.

1975 "Paleoenvironments and cultural diversity in Late Pleistocene South America: A rejoinder to Vance Haynes and a reply to Thomas Lynch". En: Quaternary Research. 5: 51-159.

1979 "The stratigraphy of Taima-Taima". En: Taima-Taima; a Late Pleistocene Paleo-Indian Kill site in Northernmost South America; final reports of 1976 excavations. Editado por Claudio Ochsenius y Ruth Gruhn. South American Quaternary Documentation Program. p. 41-42.

1986 "Paleoamerican prehistory as seen from South America". En: New evidence for the Pleistocene peopling of the Americas. Center for the study of early Man, p. 1-14.

BRYAN, Alan y Ruth GRUHN

1979 "The radiocarbon dates of Taima-Taima". En: Taima-Taima; a Late Pleistocene Paleo-Indian Kill site in Northernmost South America; final reports of 1976 excavations. Edited by Claudio Ochsenius and Ruth Gruhn. South American Quaternary Documentation Program. p. 53-58.

BRYAN, Alan; Rodolfo CASAMIQUELA, José CRUXENT, Ruth GRUHN y Claudio OSCHSENIUS

1978 “An El Jobo mastodon kill at Taima-Taima, Venezuela". En: Science, New Series, Vol. 200, nº 4347 (Jun. 16, 1978), p. 1275-1277.

CAYCHO, Félix

1957-1978 Cuaderno de ingreso de colecciones. Museo de Arqueología y Antropología de la Universidad Nacional Mayor de San Marcos.

CENTRO DE INVESTIGACIONES ANTROPOLÓGICAS ARQUEOLÓGICAS Y PALEONTOLÓGICAS (CIAAP)

s/f Registro de colecciones líticas de tipología Paleoindia en el Estado Falcón. Tomos I Y II. Centro de Investigaciones Antropológicas Arqueológicas y Paleontológicas (CIAAP), Universidad Nacional Experimental Francisco de Miranda (UNEFM), Coro. Tomo I: Folios: 01-25. Tomo II: 19-72 v.

COLLINS, Michael y Bruce BRADLEY

2008 "Evidence for pre-Clovis occupation at the Gault site (41BL323), Central Texas". En: Current Research In The Pleistocene, 25: 70-72.

CRUXENT, José María

1956 "Discovery of a Paleo-Indian lithic industry in Venezuela (Summary)". En: Proceedings of The Thirty-Second International Congress of Americanists. Copenhagen, 8-14 August 1956. Kraus Reprint, Nendeln/Liechtenstein, 1976.

1962 “Artifacts of Paleo-Indian type, Maracaibo, Zulia, Venezuela". En: American Antiquity, 27 (4): $576-$ 579.

1967 “El Paleo-Indio en Taima-Taima, Estado de Falcón, Venezuela”. En: Acta científica venezolana. Supl. 3: 3-17, 1967.

s/f "Noticia sobre tres estaciones arqueológicas con artefactos líticos de tipo Paleo-Indio, en Venezuela". Instituto de Pré-História da Universidade de Sao Paulo. En: Separata do livro origens do homen americano. II Encontros Intelectuais de São Paulo. Sob o patrocinio da UNESCO.

1979 "Stone and bone artifacts from Taima-Taima". En: Taima-Taima. A late Pleistocene Paleo-Indian Kill site in Northernmost South America; Final reports of 1976 excavations. Edited by Claudio Ochsenius and Ruth Gruhn. South American Quaternary Documentation Program. 1979: 77-89.

1983 "La técnica de talla Levalloisiense en Panamá y Venezuela". En: Comptes rendus des communications du Neuvie'me congre's international d'études des civilisations précolombines des Petites Antilles, Santo Domingo. pp. 249-256.

CRUXENT, José Maria y Patrick GALLAGHER

1979 Registro de colecciones líticas de tipología Paleoindia en el Estado Falcón. Tomo I. Centro de Investigaciones Antropológicas Arqueológicas y Paleontológicas (CIAAP), Universidad Nacional Experimental Francisco de Miranda (UNEFM), Coro. 
CRUXENT, José Maria y Carlos OSCHENIUS

1979 Registro de colecciones líticas de tipología Paleoindia en el Estado Falcón. Tomo I. Centro de Investigaciones Antropológicas Arqueológicas y Paleontológicas (CIAAP), Universidad Nacional Experimental Francisco de Miranda (UNEFM), Coro.

CRUXENT, José Maria e Irving ROUSE

1956 "A lithic industry of Paleo-Indian type in Venezuela". En: American Antiquity, Vol. 22, № 2 (Oct., 1956), 172-179.

1958 An archeological chronology of Venezuela, Panamerican Union, Science Monographs, Washington D.C.

1961 Arqueología cronológica de Venezuela. Vol.1 y Vol.2. Estudios Monográficos VI. Publicación conjunta de la UNIÖN Panamericana y del Instituto de Investigaciones Económicas de la Facultad de Economía de la Universidad de Venezuela.

DILLEHAY, Thomas

2000 The settlement of the Americas. A new prehistory. Published by Basic Books. A member of the Perseus Books Group.

GONZÁLEZ GONZÁLEZ, Arturo; Carmen ROJAS SANDOVAL, Alejandro TERRAZAS MATA, Martha BENAVENTE SANVICENTE, Wolfgang STINNESBECK, Jerónimo AVILES, Magdalena DE LOS RIOS y Eugenio ACEVEZ

2008 "The arrival of human son the Yucatan Peninsula: Evidence from submerged caves in the State of Quintana Roo, Mexico". En: Current Research In The Pleistocene, Vol. 25, p. 1-24.

GUILDERSON, Thomas; Julia COLE, y John SOUTHON

2005 "Pre-Bomb $\Delta^{14} \mathrm{C}$ variability and the Suess efect in Cariaco basin surface waters as recorded in hermatypic corals". En: Radiocarbon, Vol 47, No 1, 2005, p. 57-65.

GRUHN, Ruth y Alan BRYAN

1984 "The record of Pleistocene megafaunal extinction at Taima-taima, Northern Venezuela". En: Quaternary extinctions 5. A prehistoric revolution. The university of Arizona, Press, Tucson, Arizona. Paul S. Martin \& Richard G. Klein, Editors.

\section{HERNÁNDEZ, A}

1984 Los Caquetíos de Falcón. Instituto de Cultura del Estado Falcón (INCUDEF), Coro.

1988 Transcripción de toponímicos indígenas quechuas en el Estado Falcón, Venezuela. Fundación Hernández Baño, Linografías López, Coro.

2000 Petroglifos. Estado Falcón. Fundación Hernández Baño, Linografías López, Coro.

HUGHEN, Konrad; Jonathan OVERPECK, Scott LEHMAN, Michaele KASHGARIAN, John SOUTHON y Larry PETERSON

1998 "A new ${ }^{14} \mathrm{C}$ calibration data set For the last deglaciation based on marine varves". En: radiocarbon, Vol 40, No. 1, 1998, p. 483-494.

INIZAN, M-L; M. REDURON, H. ROCHE y J. TIXIER, J.

1995 Technologie de la Pierre Taillée. Préhistoire de la Pierre Taillée. Tome 4. Meudon: CREP.

KOSLOWSKY, Janusz y Ginter BOLESLOW

1974 Técnica de la talla y tipología de los instrumentos líticos. Instituto Cubano del Libro. Editorial pueblo y educación, La Habana. Cuba.

LIDDLE, R. A.

1928 The geology of Venezuela y Trinidad. J. P. Gowan, Fort Worth, Texas.

McCORMAC F. G; A. G. HOGG, P. G. BLACKWELL, C. E. BUCK, T. F. HIGHAM y P. J. REIMER

2004 "SHCAL04 Southern hemisphere calibration, 0-11.0 CAL KYR BP". En: Radicarbon, Vol. 46, Nr 3, 2004, p 1087-1092.

MERINO, José M.

1994 Tipología lítica. Tercera Edición. Munibe. Centro de Estudios Aranzadi.

MORÓN, Camilo

2007 Piedra Vivas en Falcón: Correspondencias entre los petroglifos y las vanguardias artísticas del siglo XX. Memoria de grado para optar al título de Magister Scientiae en Etnología. Universidad de Los Andes, Mérida. 
2010 El Estremeciendo del Velo: Interpretación simbólica de los petroglifos venezolanos. Instituto del Cultura del Estado Trujillo. Premio Bienal Nacional de Literatura Ramón Palomares, Trujillo.

2011 Informe de una cantera y un taller de tipología Paleoindia en Misaray, cerro Santa Ana, península de Paraguaná. Centro de Investigaciones Antropológicas Arqueológicas y Paleontológicas (CIAAP), Universidad Nacional Experimental Francisco de Miranda (UNEFM), Coro.

OLIVER, José

1999 Excavaciones arqueológicas en la quebrada de Balerio, golfo de Paria, Estado Sucre, Venezuela. Cuadernos Falconianos. Centro de Investigaciones Antropológicas Arqueológicas y Paleontológicas (CIAAP), Universidad Nacional Experimental Francisco de Miranda (UNEFM), Coro.

2010 El noroccidente de Venezuela. El Arte Prehispánico de Venezuela. Galería de Arte Nacional, Caracas.

OLIVER, José y Charles ALEXANDER

2003 "Ocupaciones humanas del Pleistoceno terminal en el occidente de Venezuela". En: Maguaré, Revista del Departamento de Antropología 17. Universidad Nacional de Colombia. Facultad de ciencias humanas. Departamento de Antropología.

OCHSENIUS, Claudio

1979 The present environment of the corian domain. En Taima-Taima. A late Pleistocene Paleo-Indian kill site in northermost South America-Final Reports of 1976 Excavations-Edited by Claudio Ochsenius \& Ruth Gruhn. 1979: 15-29.

PIEL-DESRUISSEAX, Jean-Luc

1989 Instrumental Prehistórico: forma, fabricación, utilización. Versión española de Valentín Villaverde Bonilla, profesor titular de prehistoria Universidad de Valencia. Masson, s.a. 1989.

POLITIS, Gustavo

1991 "Fishtail projectile points in the Southern cone of South America: An overview". En: Clovis: Origins and Adaptations, p.287-301.

QUERO, Arturo

2003 "El Vano: una nueva localidad paleo-india en el noroccidente de Venezuela". En: Maguaré, Revista del Departamento de Antropología 17. Universidad Nacional de Colombia. Facultad de ciencias humanas. Departamento de Antropología.

QUEROL, A y M. SANTONJA

1978 "Sistema de clasificación de cantos trabajados y su aplicación en yacimientos del Paleolítico antiguo de la península ibérica". En: Papeles del laboratorio de Arqueología de Valencia. SAGVNTUM 13-1978.

REIMER, P; BAILLIE, M; BARD, E; BAYLISS, A; BECK, J; BLACKWELL, P; BRONK RAMSEY C; BUCK, C; BURR G; EDWARDS, R; FRIEDRICH, M; GROOTES, P; GUILDERSON, T; HAJDAS, I; HEATON, T; HOGG, A; HUGHEN, K; KAISER, K; KROMER, B; McCormac, F; MANNING, S; REIMER, R; RICHARDS, D; SOUTHON, J; TALAMO, S; TURNEY, C; van der PLICHT, J; WEYHENMEYER, C.

2009 "INCAL09 and MARINE09 Radiocarbon age calibration curves, 0-50,000 Years CAL BP". En: Radiocarbon, 51 (4): 111-1150.

ROUSE, Irving y José María CRUXENT

1957 "Further comment on the finds at El Jobo, Venezuela". En: American Antiquity, Vol. 22, № 4 (Apr., 1957), 412.

1963a "Some recent radiocarbon dates for Western Venezuela". En: American Antiquity, Vol. 28, № 4 (Apr., 1963), pp. 537-540.

1963b "Recientes datos sobre fechas arqueológicas por el método de C14 en el Occidente de Venezuela". En: Acta Científica Venezolana. Supl. 1: 3-10, 1963.

1963c Venezuelan archaeology. Yale University Press, New Haven and London.

1963d Arqueología venezolana. Edición española, editada bajo los auspicios del Instituto Venezolano de Investigaciones Científicas, de la versión original en inglés publicada por Yale University Press, New Haven y Londres, 1963.

SCHWARCK, A.

1956 Introducción a las principales provincias fisiográficas de Venezuela. Léxico Estratigráfico de Venezuela, Bol. Geol., Ministerio de Minas e Hidrocarburos, Caracas. 
SONNEVILLE-BORDES (D.de) y PERROT

1956 "Lexique typologique du Paleolithique Superior". En: Bulletin de La Société Préhistorique Française. 53: 408-412.

SZABADICS, Miklos

1997 Arqueología de la prehistoria de Venezuela. Publicaciones de la gobernación del Estado Aragua, Maracay 1997.

SZABADICS, Miklos y R. TORREALBA

2000 Informe de la colección de lítica tallada del Centro de Investigaciones Antropológicas, Arqueológicas y Paleontológicas. Centro de Investigaciones Antropológicas Arqueológicas y Paleontológicas (CIAAP), Universidad Nacional Experimental Francisco de Miranda (UNEFM), Coro.

TAMERS, M. A.

1971 “Instituto Venezolano de Investigaciones Científicas Natural Radiocarbon Measurements V”. En: Radiocarbon. 13: 32-44.

TAYLOR, R. E.

1987 Radiocarbon dating an archaeological perspective. Academic Press, INC.

UGARTE, Julissa

1997 Inventario del material lítico II (1997-1998). Museo de Arqueología y Antropología de la UNMSM.

VILLAVICENCIO, José Maria

1985 “Análisis geomorfológico de la península de Paraguaná”. En: Revista Geográfica, № 102, Venezuela (Julio-Diciembre 1985), pp. 17-27. Published by: Pan American Institute of Geography and History.

WATERS, Michael; Thomas STAFFOD, Gregory MCDONALD, Carl GUSTAFSON, Morten RASMUSSEN, Enrico CAPPELLINI, Jesper OLSEN, Damian SZKLARCZYK, Lars JENSEN, Thomas GILBERT y Eske WILLERSLEV

2011 "Pre-Clovis mastodon hunting 13,800 years ago at the Manis site, Washington". En: Science, Vol. 334: 351-353. 